\title{
CONSOLIDAÇÃO DE ROTINA ANALÍTICA PARA QUANTIFICAÇÃO DE FÓSFORO TOTAL EM CORPOS HÍDRICOS: Impactos para a Gestão dos Recursos Hídricos
}

\author{
ANALYTICAL PROCEDURE CONSOLIDATION FOR THE \\ TOTAL PHOSPHORUS QUANTIFICATION IN WATER \\ BODIES: Impact for the Water Resources Management
}

\begin{abstract}
Fernanda Batista Guimarães Cipriano ${ }^{1}$, Caroline Kozak ${ }^{1}$, Luciane Lemos do Prado ${ }^{1}$ e Cristovão Vicente Scapulatempo Fernandes ${ }^{1}$

${ }^{1}$ Universidade Federal do Paraná, Curitiba-PR, Brasil; e-mails: guimaraes.fernandab@gmail.com, carolkozak05@gmail.com, lulepr1074@gmail.com,cris.dhs@ufpr.br
\end{abstract}

Como citar: Cipriano, F. B. G.; Kozak, C.; Prado, L. L.; Fernandes, C.V. S. Consolidação de rotina analítica para quantificação de fósforo total em corpos hídricos: impactos para a gestão dos recursos hídricos. Revista de Gestão de Água da América Latina, v. 16, e11, 2019.

https://doi.org/10.21168/rega.v16e11.

RESUMO: 0 entendimento da dinâmica do fósforo no ecossistema e sua correta e precisa quantificação é fundamental para adequada tomada de decisão na gestão de recursos hídricos. Desta forma, o objetivo deste trabalho foi avaliar o melhor método analítico para quantificação do fósforo por meio de três metodologias de digestão ácida distintos de extração de fósforo total. Os locais de estudo foram o Rio Barigui e Rio Passaúna que possuem diferentes usos e ocupação da terra, bem como usos da água. Os resultados mostraram que todos os métodos propostos apresentam boa reprodutibilidade com $\mathrm{R}^{2}$ maior que 0.98 , para baixas e altas concentrações. Contudo, na quantificação das amostras ambientais o método 2 apresentou resultados mais satisfatório, no qual se destacam o menor volume de amostra e reagentes utilizados, menor tempo de digestão e boa precisão e reprodutibilidade da concentração de P das amostras. 0 uso inadequado de um procedimento analítico ou de uma curva de calibração inadequada pode subestimar a quantificação de $\mathrm{P}$ em amostras com baixas concentrações em cerca de 70\%, ressaltando a importância de um bom planejamento experimental e preocupação com a qualidade da informação gerada.

PALAVRAS-CHAVE: Digestão Ácida, Metodologia, Qualidade da Informação

ABSTRACT: Understanding the phosphorus dynamics in the ecosystem and its correct and accurate quantification is fundamental for proper decision making in water resources management. Thus, the aim of this study was to evaluate the best analytical method for quantifying phosphorus using three distinct acid digestion methodologies for total phosphorus extraction. The study areas were the Barigui and Passaúna Rivers which have different land use and soil occupation, as well as water uses. The results showed that all proposed methods have good reproducibility with $\mathrm{R}^{2}$ greater than 0.98 , for low and high concentrations. However, in the samples quantification, method 2 presented the most satisfactory results, in which the smaller sample volume and reagents used, shorter digestion time and good precision and reproducibility of P concentration of the samples stand out. Improper use of an analytical procedure or calibration curve may underestimate the quantification of $\mathrm{P}$ in samples with low concentrations by about $70 \%$, highlighting the importance of good experimental design and concern for the quality of the information generated.

KEY-WORDS: Acid Digestion, Methodology, Information Quality 


\section{INTRODUÇÃO}

0 fósforo (P) é um dos elementos mais dispersos na natureza, devido a sua origem mineral e dado a sua importância nas estruturas de moléculas do metabolismo celular. Por ser um nutriente presente em todos os organismos vivos usado para o crescimento e para o transporte de energia, é também o nutriente limitante em ambientes aquáticos (Worsfold et al., 2016). Devido ao seu ciclo sedimentar, o $\mathrm{P}$ circula entre os organismos vivos e meio terrestre e seus principais fluxos são encontrados entre a biota do solo e o solo, biota marinha e o oceano, e vão para esses meios através da erosão e intemperismo das rochas. A principal fonte natural de $\mathrm{P}$ para plantas e animais provém das rochas, onde o fósforo é encontrado na forma de fosfatos ( $\left.\mathrm{PO}_{4}^{3-}\right)$. Em águas naturais, o P é encontrado como ortofosfatos inorgânicos, polifosfatos, fosfatos orgânicos e como partículas, que pode incluir argilas e produtos orgânicos, assim como P inorgânico, precipitados de matérias biológicas (Worsfold et al., 2016).

0 fósforo está presente em importantes compostos biológicos, como o DNA e as enzimas que são responsáveis pela transferência de energia em processos biológicos das células vivas (adenosina trifosfato e adenosina difosfato, por exemplo). Para as plantas auxilia no crescimento, pois estas absorvem o fósforo do solo na forma de íons fosfatos, através de suas raízes, que é então transportado para as moléculas biológicas presentes nas suas folhas (Veiga, 2010). Ao se alimentarem das plantas, os animais acabam obtendo o fosfato, que posteriormente será transferido ao homem através da cadeia alimentar. 0 fósforo será devolvido ao meio através da decomposição de animais, na forma de resíduos e tecidos mortos, causada pela ação das bactérias fosfolizantes. Esses resíduos, ao serem carregados pela ação da chuva, irão para lagos, rios e posteriormente para os mares como fosfatos dissolvidos, gerando sedimentos marinhos fosfatados, que futuramente gerarão novas rochas de fosfato (Girard \& Oliveira, 2013), finalizando então o seu ciclo natural.

Contudo, a contribuição de fósforo no ecossistema vem se intensificando cada vez mais, através das atividades antrópicas como os processos de fertilização, mineração, lançamento de efluentes industriais e, principalmente, o de esgotos domésticos. Essas atividades têm ocasionado a alterações no meio ambiente, sendo o retorno ao seu ciclo elevado, levando aos processos de eutrofização (Quevedo \& Paganini, 2011; Veiga, 2010). Sendo assim, ressalta-se a importância do estudo do fósforo em ambientes aquáticos de água doce, considerando os impactos causados pelas atividades humanas.

$\mathrm{O}$ entendimento da dinâmica do $\mathrm{P}$ no ecossistema e sua quantificação, além de ser motivada pelos impactos causados pelas atividades antrópicas, também está associada com a precisa mensuração deste elemento para fins de gestão de recursos hídricos. A resolução CONAMA $N^{\circ} 357 / 2005$ (Brasil, 2005) que determina os parâmetros de classificação dos corpos hídricos em classes estabelece limites para fósforo total em diferentes ambientes (lêntico, lótico e intermediário), com concentrações que variam de altas a baixas. Neste sentido, como afirma Worsfold et al. (2016), é preciso desenvolver métodos analíticos sensíveis e precisos para determinações das concentrações de fósforo em amostras, visto que muitas vezes a quantificação deste nutriente é complexa devido a sua baixa concentração presente nos locais de estudo. A determinação adequada das concentrações de fósforo é importante para levar a correta quantificação do elemento no sistema aquático, refinando assim a compreensão do seu comportamento e disponibilidade no ecossistema.

Portanto, o objetivo deste trabalho é avaliar o melhor método analítico para quantificação do fósforo em amostras de rios e reservatórios, com concentrações baixas e altas, por meio de três métodos distintos de extração de fósforo total. Buscou-se analisar o método mais viável para a determinação do P na amostra, considerando suas características, bem como a curva de calibração adequada para obtenção de valores de concentrações confiáveis.

\section{MATERIAL E MÉTODOS}

\section{ÁREA DE ESTUDO}

O estudo foi realizado no Rio Barigui e no Rio Passaúna, apresentados na Figura 1. 0 Rio Barigui possui extensão de $67 \mathrm{~km}$, com área total de drenagem de $279 \mathrm{~km}^{2}$, e é afluente da margem direita do rio Iguaçu. Na região norte da Bacia, pertencente ao município de Almirante Tamandaré, o uso e ocupação da terra predominante é o uso rural, com urbanização dispersa. Na região média e no trecho final da bacia, que contém parte do município de Curitiba e de Araucária, respectivamente, a 
ocupação urbana acentua-se, com domínio dos usos residencial, comercial e de serviços, ocasionando o aumento da quantidade de lançamento de esgoto domésticos nos corpos hídricos desta região (Froehner \& Martins, 2008; Araucária, 2018).

0 Rio Passaúna possui extensão de aproximadamente $48 \mathrm{~km}$, com área de drenagem de $217 \mathrm{~km}^{2}$. Também é um afluente da margem direita do Rio Iguaçu (Paraná, 2002), abrangendo os municípios de Curitiba e Araucária. Nesta bacia localiza-se o Reservatório Passaúna, com aproximadamente $20 \mathrm{~m}$ de profundidade, fornece água para abastecimento da Região Metropolitana de Curitiba, juntamente com os reservatórios Piraquara e Iraí (Coquemala, 2005). Esta bacia possui baixa ocupação urbana, sendo de uso predominantemente rural, mas há alguns centros urbanos por meio dela, onde a maior parte se localiza na região do município de Araucária (Paraná, 2002).

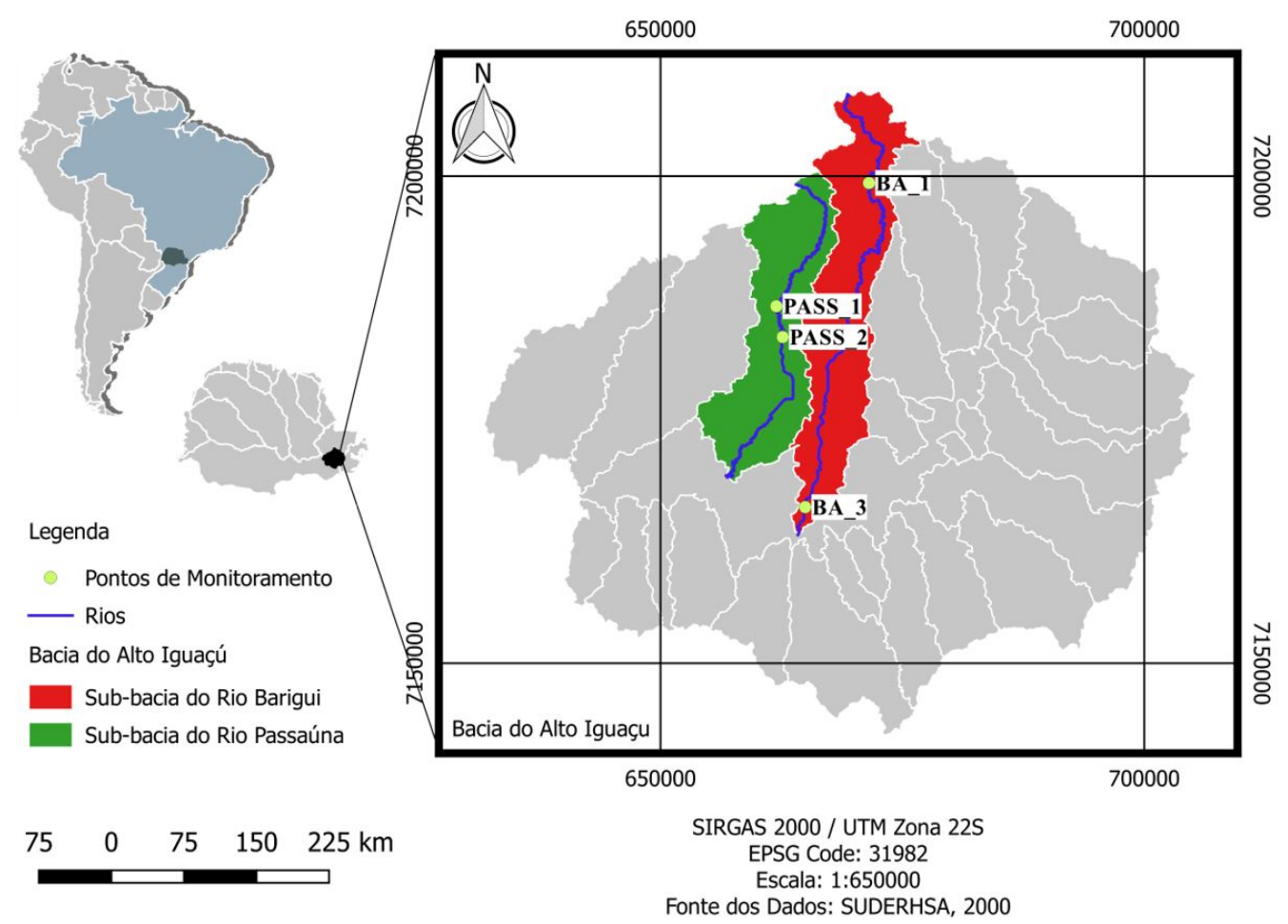

FIGURA 1 - Localização da Bacia do Rios Barigui e Passaúna e dos quatro pontos de monitoramento estudados. FIGURE 1 - Location of the Barigui and Passaúna River Basin and the four monitoring points studied. Fonte: Os autores (2018).

Source: The Authors (2018)

\section{AMOSTRAGEM}

Foram escolhidos 4 pontos de monitoramento: dois localizados no Rio Barigui, denominado BA1 e BA3, e dois no Rio Passaúna, denominados PASS_1 e PASS_2 A Tabela 1 indica os pontos de coleta do Rio Barigui e Passaúna com suas respectivas coordenadas e características. Foi realizada uma coleta por mês, durante o período de setembro a dezembro de 2017. Estes pontos foram escolhidos devidos às diferentes características de uso e ocupação da terra do entorno que produz diferentes entradas de carga de fósforo, abrangendo concentrações baixas (pontos BA1, PASS_1 e PASS_2) e concentrações altas (BA3).

As amostras foram coletadas manualmente, nos pontos supracitados e transferidas para garrafas de Polietileno de 1L. As garrafas foram pré-descontaminadas através da imersão em solução de ácido clorídrico (5\%) com posterior enxágue em água destilada e secagem na estufa. As amostras permaneceram refrigeradas $\left(\sim 4^{0} \mathrm{C}\right)$ até o momento da análise. Assim como as garrafas de coleta, todos os materiais utilizados para o procedimento foram lavados em $\mathrm{HCl} 1 \mathrm{~N}$ aquecido à $150{ }^{\circ} \mathrm{C}$. Após a lavagem em ácido aquecido, os materiais foram enxaguados com água destilada e secos em estufa.

A quantificação de Fósforo Total foi realizada pelos métodos: (i) Digestão Ácida de $\mathrm{HNO}_{3}$ e $\mathrm{H}_{2} \mathrm{SO}_{4}$, denominado de método 1; (ii) Digestão com Persulfato, denominado método 3, ambos propostos por APHA (2012) e (iii) método proposto por Prado (2015), denominado método 2. 
TABELA 1 - Pontos de coleta na Bacia do Rio Barigui e Passaúna (coordenadas UTM) e suas respectivas características.

TABLE 1 - Monitoring sites in Barigui and Passaúna River Basin (UTM coordinates) and their respective characteristics.

\begin{tabular}{|c|c|c|c|c|c|}
\hline \multicolumn{6}{|c|}{ PONTOS DE COLETA } \\
\hline \multicolumn{3}{|c|}{ Bacia do Rio Barigui } & \multicolumn{3}{|c|}{ Bacia do Rio Passaúna } \\
\hline Ponto & Características & Coordenadas (m) & Ponto & Características & Coordenadas (m) \\
\hline BA1 & $\begin{array}{l}\text { Município de } \\
\text { Almirante } \\
\text { Tamandaré } \\
\end{array}$ & $\begin{array}{l}671552 \mathrm{X} \\
7199303 \mathrm{Y}\end{array}$ & PASS_1 & $\begin{array}{l}\text { Sobre rodovia BR } \\
\qquad 277\end{array}$ & $\begin{array}{l}661973 \mathrm{X} \\
7186651 \mathrm{Y}\end{array}$ \\
\hline BA3 & $\begin{array}{l}\text { Foz do Rio } \\
\text { Barigui com o } \\
\text { Rio Iguaçu }\end{array}$ & $\begin{array}{c}664960 \mathrm{X} \\
7166028 \mathrm{Y}\end{array}$ & PASS_2 & $\begin{array}{c}\text { Entrada do } \\
\text { Reservatório } \\
\text { Passaúna, sobre } \\
\text { ponta Ferraria }\end{array}$ & $\begin{array}{c}662627 \mathrm{X} \\
7183488 \mathrm{Y}\end{array}$ \\
\hline
\end{tabular}

\section{MÉTODOS}

\section{Curvas de Calibração}

A calibração do método foi feita através de duas curvas de calibração padrão para concentrações baixas (de 0 a $0,25 \mathrm{mg} \mathrm{L}^{-1}$ ) e altas (de 0 a 1,5 $\mathrm{mg} \mathrm{L}^{-1}$ ). Esta divisão aconteceu devido às diferenças observadas na inclinação das curvas e para que se possa obter uma melhor cobertura na quantificação do analito, principalmente para as amostras que possuem concentrações baixas. A partir da solução padrão (50 mg $\mathrm{P} \mathrm{L}^{-1}$ ) preparou-se, em balões volumétricos de $50 \mathrm{~mL}$, as seguintes curvas de calibração, conforme Tabela 2. 0 volume final foi completado com água destilada.

TABELA 2 - Curva de calibração de concentrações baixas e altas de fósforo total

TABLE 2 - Calibration curves for low and high concentration of total phosphorus

\begin{tabular}{c|c|c|c}
\hline \multicolumn{2}{c}{ Curva Baixa } & \multicolumn{2}{c}{ Curva Alta } \\
\cline { 1 - 2 } $\begin{array}{c}\text { Concentração P-PO4-3 } \\
\text { final (mg.L-1) }\end{array}$ & $\begin{array}{c}\text { Volume de solução } \\
\text { padrão (mL) }\end{array}$ & $\begin{array}{c}\text { Concentração P-PO4-3 } \\
\text { final (mg.L-1) }\end{array}$ & $\begin{array}{c}\text { Volume de solução } \\
\text { padrão (mL) }\end{array}$ \\
\hline 0,00 & - & 0,00 & - \\
\hline 0,025 & 0,025 & 0,100 & 0,100 \\
\hline 0,050 & 0,050 & 0,300 & 0,300 \\
\hline 0,075 & 0,075 & 0,400 & 0,400 \\
\hline 0,100 & 0,100 & 0,500 & 0,500 \\
\hline 0,150 & 0,150 & 0,700 & 0,700 \\
\hline 0,200 & 0,200 & 0,900 & 0,900 \\
\hline 0,250 & 0,250 & 1,500 & 1,500 \\
\hline
\end{tabular}

A mesma curva de calibração foi reproduzida em todos os métodos testados. Em cada método, os padrões foram preparados e submetidos às mesmas condições das amostras. Para cada ponto da curva de calibração foram realizadas digestões em triplicata. A partir de cada digestão foram retiradas cinco alíquotas para quantificação, totalizando quinze réplicas. Essa condição foi imposta para saber a precisão dos valores obtidos, pois se sabe que as réplicas melhoram a qualidade dos resultados e fornecem uma medida de confiabilidade (Skoog et al., 2006).

\section{Método 1: Método 4500-P B proposto por APHA (2012)}

Este método consiste na digestão ácida através de $\mathrm{HNO}_{3}$ e $\mathrm{H}_{2} \mathrm{SO}_{4}$ e posterior quantificação colorimétrica pelo método do ácido ascórbico. Utilizou-se $50 \mathrm{~mL}$ de amostra, a qual foi transferida para o erlenmeyer de $125 \mathrm{~mL}$, adicionou-se $1 \mathrm{~mL}$ de $\mathrm{H}_{2} \mathrm{SO}_{4}$ (p.a.) e $5 \mathrm{~mL}$ de $\mathrm{HNO}_{3}$ (p.a.). Em seguida, colocaram-se as amostras na chapa de aquecimento, em aproximadamente $200^{\circ} \mathrm{C}$, até que o volume se reduzisse em aproximadamente $1 \mathrm{~mL}$. Todas as digestões foram feitas em triplicata. Após as amostras terem atingido a temperatura ambiente, lavou-se o erlenmeyer com água destilada e 
transferiu-se o volume resultante para o balão de $50 \mathrm{~mL}$. Neutralizou-se a amostra com $\mathrm{NaOH} 5 \mathrm{~N}$ e $\mathrm{H}_{2} \mathrm{SO}_{4} 5 \mathrm{~N}$. Avolumou-se o balão até o menisco e retirou-se alíquotas de $5 \mathrm{~mL}$ em quintuplicata. Em seguida, adicionou-se $1 \mathrm{~mL}$ da solução reativa combinada do método do ácido ascórbico, homogeinizou-se e esperou-se 10 min para a leitura no espectrofotômetro $(\lambda=880 \mathrm{~nm})$.

\section{Método 2: Método proposto por Prado (2015).}

0 método consiste da digestão ácida de persulfato de potássio com ácido clorídrico, proposto por Prado (2015). Utilizou-se $25 \mathrm{~mL}$ de amostra, a qual foi transferida para o erlenmeyer de $125 \mathrm{~mL}$, adicionou-se $5 \mathrm{~mL}$ de $\mathrm{HCl}$ 1,0 mol/L e 0,8 mL da solução de persulfato. A solução de persulfato deve ser preparada adicionando 2,5 mL de ácido sulfúrico (p.a.) e 2,5 g de persulfato de potássio em um balão volumétrico de $50 \mathrm{~mL}$. Em seguida, colocaram-se as amostras na chapa de aquecimento, em aproximadamente $200^{\circ} \mathrm{C}$, até que o volume se reduzisse em $5 \mathrm{~mL}$. Após as amostras terem atingido a temperatura ambiente, lavou-se o erlenmeyer com água destilada e transferiu-se o volume resultante para o balão de $25 \mathrm{~mL}$. Neutralizou-se a amostra com $\mathrm{NaOH} 5 \mathrm{~N} \mathrm{e} \mathrm{H}_{2} \mathrm{SO}_{4} 5 \mathrm{~N}$. Avolumou-se o balão até o menisco e retirou-se cinco alíquotas de $5 \mathrm{~mL}$. Em seguida, adicionou-se $1 \mathrm{~mL}$ da solução reativa combinada do método do ácido ascórbico dado por APHA (2012), homogeinizou-se e esperouse $10 \mathrm{~min}$ para a leitura no espectrofotômetro $(\lambda=880 \mathrm{~nm})$.

\section{Método 3: Método 4500-P B. - Digestão Persulfato (APHA, 2012).}

Este método consiste na digestão ácida através das soluções de $\mathrm{H}_{2} \mathrm{SO}_{4} 10 \mathrm{~N}$ e $\mathrm{K}_{2} \mathrm{~S}_{2} \mathrm{O}_{8}$ e posterior quantificação colorimétrica. Utilizou-se $50 \mathrm{~mL}$ de amostra, a qual foi transferida para o erlenmeyer de $125 \mathrm{~mL}$ e em seguida adicionou-se $1 \mathrm{~mL}$ da solução de $\mathrm{H}_{2} \mathrm{SO}_{4}$ e $10 \mathrm{~mL}$ da solução de $\mathrm{K}_{2} \mathrm{~S}_{2} \mathrm{O}_{8}$. Para a solução de $\mathrm{K}_{2} \mathrm{~S}_{2} \mathrm{O}_{8}$ adicionou-se $50 \mathrm{~g}$ de persulfato em aproximadamente $600 \mathrm{~mL}$ de água destilada em um balão de 1L. Em seguida, colocaram-se as amostras na chapa de aquecimento, em aproximadamente $200^{\circ} \mathrm{C}$, até que o volume se reduzisse em aproximadamente $5 \mathrm{~mL}$. Após as amostras terem atingido a temperatura ambiente, lavou-se o erlenmeyer com água destilada e transferiu-se o volume resultante para o balão de $50 \mathrm{~mL}$. Neutralizou-se a amostra com $\mathrm{NaOH} 5 \mathrm{~N}$ e $\mathrm{H}_{2} \mathrm{SO}_{4} 5 \mathrm{~N}$. Avolumou-se o balão até o menisco e retirou-se cinco alíquotas de $5 \mathrm{~mL}$. Em seguida, adicionou-se $1 \mathrm{~mL}$ da solução reativa combinada do método do ácido ascórbico, homogeinizou-se e esperou-se 10 min para a leitura no espectrofotômetro $(\lambda=880 \mathrm{~nm})$.

\section{Variações nas concentrações de fósforo nas diferentes matrizes ambientais de água}

Algumas amostras apresentaram concentração de fósforo muito baixa, tornando difícil a quantificação pelos métodos convencionais. Por isso, para cada método proposto, foram realizados quatro tipos de testes, variando as condições da amostra. Outro fator importante na escolha do método é a composição. Os ensaios de quantificação foram realizados nas seguintes condições:

1. Amostra Inteira $\left(\boldsymbol{A}_{\boldsymbol{I}}\right)$ : Consiste em analisar uma alíquota da amostra pura (tal qual), sem diluição, concentração ou adição de padrão;

2. Enriquecimento com Padrão de $100 \mathrm{mg} \mathrm{P} \mathrm{L}^{-1}\left(A_{P}\right)$ : foi adicionado ao volume de amostra inteira a concentração de $100 \mathrm{mg} \mathrm{P} \mathrm{L}^{-1}$. Este procedimento foi realizado para facilitar a quantificação de $\mathrm{P}$ nos casos em que as amostras apresentem concentrações baixas (menores que $0,15 \mathrm{mg} \mathrm{P} \mathrm{L}^{-1}$ );

3. Amostra concentrada 2 vezes $\left(A_{2 x}\right)^{1}$ : foi utilizado 2 vezes o volume da amostra inteira, e deixando reduzir pela metade, com aquecimento em chapa. 0 procedimento consiste em deixar a amostra evaporar, em chapa aquecedora, até que o volume inicial fique reduzido pela metade, consequentemente as concentrações de $P$ ficam concentradas em 2 vezes.;

4. Amostra concentrada 4 vezes $\left(\boldsymbol{A}_{4 x}\right)$ : foi utilizado 4 vezes o volume da amostra inteira, sendo reduzida em 1/4, com aquecimento em chapa. Resultando em concentração da amostra de 4 vezes.

\footnotetext{
1 Por exemplo, se o método indica um volume inicial $\left(A_{I}\right)$ de $25 \mathrm{~mL}$, para a variável $A_{2 x}$ o volume inicial deve ser de $50 \mathrm{~mL}$, assim como para a variável $A_{4 x}$ o volume inicial deverá ser $100 \mathrm{~mL}$. Em ambos os casos o aquecimento em chapa aquecedora deverá acontecer até a redução em aproximadamente $10 \mathrm{~mL}$ para posteriores etapas do determinado procedimento analítico.
} 


\section{Planejamento Experimental}

A partir dos distintos usos do solo das áreas de estudo consideradas, foi usada a curva de calibração para baixas concentrações para os pontos BA1, PASS_1 e PASS_2, e a curva de altas concentrações para o ponto BA3. Para cada amostra analisada, em todos os métodos, foram realizadas 3 digestões. De cada digestão realizada, foram retiradas 5 alíquotas para quantificação, ao todo, foram avaliados 15 valores. No ponto BA3 não foi realizado o teste de concentração $4 \mathrm{x}$, devido às altas concentrações de $\mathrm{P}$ encontradas inicialmente. No ponto PASS_2 não foi realizado o método de digestão 3 pois não houve coleta para a realização deste método.

\section{RESULTADOS E DISCUSSÃO}

\section{Resultados}

\section{Curvas de Calibração}

A fim de se obter uma quantificação mais adequadas e efetiva do analito, nas diferentes matrizes de água, foram feitas curvas de calibração para concentrações de 0,00 até $0,25 \mathrm{mg} \mathrm{P} \mathrm{L}^{-1}$ (baixas concentrações) e de 0,00 até $1,50 \mathrm{mg} \mathrm{P} \mathrm{L}^{-1}$ (altas concentrações). A Figura 2 mostra as curvas de calibração baixa (2a) e alta (2b), respectivamente, para os três métodos testados. A Tabela 3 sumariza os coeficientes de correlação de cada curva de calibração testada. 0 detalhamento dos dados gerados para cada réplica de digestão, e para cada método analítico estudado, é apresentado no Material Complementar deste trabalho.

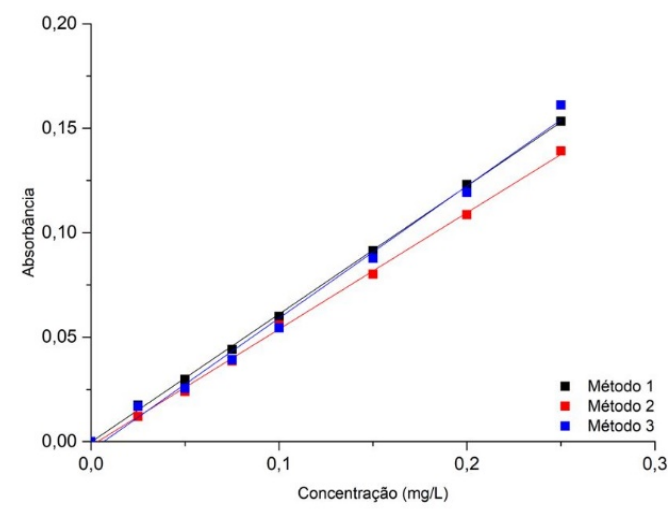

2a - Curva de calibração de concentrações baixas ( 0 a $0,25 \mathrm{mg} / \mathrm{L})$

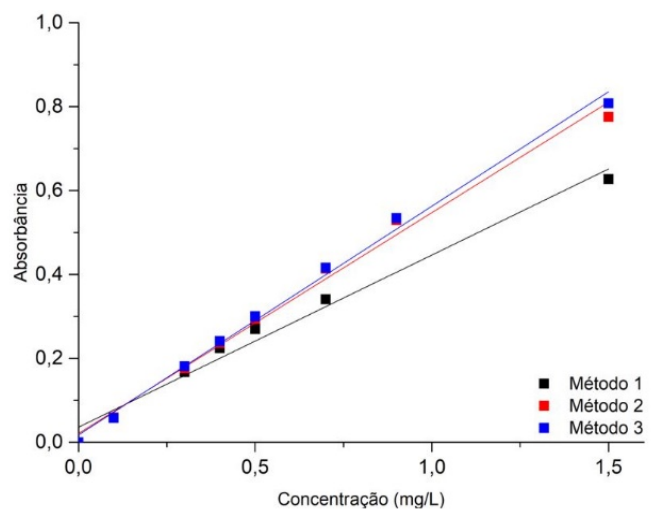

2b - Curva de calibração de concentrações altas (0 a 1,5 $\mathrm{mg} / \mathrm{L})$

FIGURA 2 - Curvas de calibração de baixas e altas concentrações para os três métodos de digestão ácida propostos

FIGURE 2 - Calibration curves of low and high concentration for the three acid digestions methods proposed

Os coeficientes de correlação $\left(\mathrm{R}^{2}\right)$ apresentaram bom ajuste para as curvas de baixas concentrações, de 0,99 para todos os métodos. Para as curvas de altas concentrações apenas os métodos 2 e 3 apresentaram $\mathrm{R}^{2}$ de 0,99. 0 método 3 apresentou $\mathrm{R}^{2}$ de 0,98. Da mesma forma, a inclinação da curva nos indica a sensibilidade analítica através dos valores de coeficiente angular, pois este é diretamente proporcional à sensibilidade analítica ( $\uparrow$ coeficiente angular $\uparrow$ sensibilidade analítica). Tais sensibilidades estão associadas às variações da concentração do analito (Skoog et al., 2006). Ao analisar as curvas obtidas, pode-se notar que as curvas que possuem maior sensibilidade são referentes às concentrações baixas (coeficiente angular com valor médio de 0.60 ), em relação às de concentrações altas (coeficiente angular com valor médio de 0,49 ). Isto pode estar associado a representatividade da cobertura analítica distinta entre as curvas impostas.

A curva de calibração de baixa concentrações apresenta uma variação pequena entre as concentrações propostas e uma abrangência menor da faixa de quantificação $\left(0\right.$ a $\left.0,25 \mathrm{mg} \cdot \mathrm{L}^{-1}\right)$, sendo a curva mais inclinada. Em contrapartida, a curva de calibração de altas concentrações apresenta uma variação maior entre as concentrações propostas e uma abrangência maior da faixa de 
quantificação ( 0 a 1,5 mg. $\mathrm{L}^{-1}$ ), sendo a curva menos inclinada. Portanto, entende-se que a curva de concentrações baixas possui maior sensibilidade analítica devido à proximidade das concentrações e maiores probabilidades de erros analíticos aleatórios envolvidos para a quantificação de concentrações muito próximas ao limite de detecção do método. Apesar disso, todas as curvas apresentam boa representatividade com $\mathrm{R}^{2}$ maior que 0,98 em todos os métodos analisados.

TABELA 3 - Equação da reta $(y=a x+b)$ e coeficientes de correlação das curvas de calibração de baixas e altas concentrações para os três métodos de digestão ácida testados

TABLE 3 - Linear equation $(y=a x+b)$ and correlation coefficients of low and high concentration calibration curves for the three acid digestion methods tested

\begin{tabular}{c|c|c|c}
\hline \multicolumn{2}{c}{ Método 1 } & Método 2 & Método 3 \\
\hline \multirow{2}{*}{ Curva Baixa } & $\mathrm{y}=0,61 \mathrm{x}-0,00022$ & $\mathrm{y}=0,56 \mathrm{x}-0,0019$ & $\mathrm{y}=0,63 \mathrm{x}-0,0042$ \\
& $\mathrm{R}^{2}=0,99939$ & $\mathrm{R}^{2}=0,99868$ & $\mathrm{R}^{2}=0,99154$ \\
\hline \multirow{2}{*}{ Curva Alta } & $\mathrm{y}=0,41 \mathrm{x}+0,036$ & $\mathrm{y}=0,53 \mathrm{x}+0,020$ & $\mathrm{y}=0,54 \mathrm{x}+0,017$ \\
& $\mathrm{R}^{2}=0,98125$ & $\mathrm{R}^{2}=0,99025$ & $\mathrm{R}^{2}=0,99441$ \\
\hline
\end{tabular}

\section{Quantificação das amostras}

Um indicativo para determinar o fósforo, na curva analítica mais adequada, foi considerar o uso do solo das áreas de estudo, visto que a contribuição de nutrientes e contaminantes na água está diretamente relacionada. Na Tabela 4 estão apresentados os valores médios \pm desvio padrão das concentrações, determinado em cada um dos métodos testados. 0 detalhamento dos dados gerados para cada réplica de digestão, e para cada método analítico estudado, é apresentado no Material Complementar deste trabalho.

TABELA 4 - Concentração de fósforo total ( $\left.\mathrm{P}_{\mathrm{T}}\right)$ determinado pelos métodos de digestão ácida 1, 2 e 3.

TABLE 4 - Total Phosphorus concentration measured by acid digestion 1, 2 and 3.

\begin{tabular}{|c|c|c|c|}
\hline Concentração de $\mathrm{P}\left(\mathrm{mg} \mathrm{L}^{-1}\right)$ & Método 1 & Método 2 & Método 3 \\
\hline \multicolumn{4}{|c|}{$\overline{B A 1}$} \\
\hline $\mathrm{A}_{\mathrm{I}}$ & $0.05 \pm 0.01$ & $0.06 \pm 0.01$ & $0.06 \pm 0.03$ \\
\hline $\mathrm{AP}_{\mathrm{P}}$ & $0.04 \pm 0.01$ & $0.16 \pm 0.02$ & $0.06 \pm 0.01$ \\
\hline $\mathrm{A}_{2 \mathrm{x}}$ & $0.05 \pm 0.01$ & $0.06 \pm 0.01$ & $0.05 \pm 0.01$ \\
\hline $\mathrm{A}_{4 \mathrm{x}}$ & $0.05 \pm 0.01$ & $0.03 \pm 0.02$ & $0.04 \pm 0.02$ \\
\hline \multicolumn{4}{|c|}{ BA3 } \\
\hline $\mathrm{A}_{\mathrm{I}}$ & $0.25 \pm 0.04$ & $0.32 \pm 0.03$ & $0.40 \pm 0.03$ \\
\hline $\mathrm{AP}_{\mathrm{P}}$ & $0.33 \pm 0.07$ & $0.38 \pm 0.01$ & $0.40 \pm 0.02$ \\
\hline $\mathrm{A}_{2 \mathrm{x}}$ & $0.11 \pm 0.02$ & $0.32 \pm 0.06$ & $0.36 \pm 0.06$ \\
\hline $\mathrm{A}_{4 \mathrm{x}}$ & & $0.26 \pm 0.06$ & \\
\hline \multicolumn{4}{|c|}{ PASS_1 } \\
\hline $\mathrm{A}_{\mathrm{I}}$ & $0.05 \pm 0.01$ & $0.06 \pm 0.02$ & $0.08 \pm 0.01$ \\
\hline$A_{P}$ & $0.04 \pm 0.01$ & $0.17 \pm 0.02$ & $0.06 \pm 0.01$ \\
\hline $\mathrm{A} 2 \mathrm{x}$ & $0.05 \pm 0.003$ & $0.06 \pm 0.01$ & $0.08 \pm 0.02$ \\
\hline $\mathrm{A}_{4 \mathrm{x}}$ & & $0.07 \pm 0.09$ & $0.09 \pm 0.03$ \\
\hline \multicolumn{4}{|c|}{ PASS_2 } \\
\hline$A_{I}$ & $0.06 \pm 0.02$ & $0.04 \pm 0.01$ & \\
\hline $\mathrm{A}_{\mathrm{P}}$ & $0.06 \pm 0.01$ & $0.15 \pm 0.01$ & \\
\hline $\mathrm{A}_{2 \mathrm{x}}$ & $0.06 \pm 0.004$ & $0.05 \pm 0.02$ & \\
\hline $\mathrm{A}_{4 \mathrm{x}}$ & & $0.05 \pm 0.03$ & \\
\hline
\end{tabular}

Nota: $A_{I}=$ Amostra inteira. $A_{P}=$ Amostra com adição do padrão de $100 \mathrm{mg} \mathrm{L}^{-1}$ de $P . A_{2 x}=$ Amostra concentrada 2 vezes. $A_{4 x}=$ Amostra concentrada 4 vezes.

É possível observar que o ponto BA1 possui concentrações médias cerca de 6 vezes menor que as concentrações médias no ponto BA3. Este fato está diretamente associado aos diferentes usos do solo em cada área de drenagem. Enquanto o ponto BA1 está localizado em área menos urbanizada, apresenta $\mathrm{pH}$ elevado e recebe influência do aquífero Karst, rico em carbonatos, o ponto BA3 se localiza em área urbana densa e próximo a despejo de esgotos domésticos e industriais, justificando-se os maiores valores de P encontrados. Para os pontos do Rio Passaúna, observa-se concentrações 
baixas justificadas pela pouca influência urbana que a bacia recebe e considerando que este manancial é destinado ao abastecimento público.

Em relação aos métodos de digestão observa-se que para a mesma amostra, e para as variáveis $A_{I}, A_{2 x}$ e $A_{4 x}$, a reprodutibilidade da quantificação foi similar. Apenas a variável $A_{P}$ do método 2 para baixas concentrações houveram as maiores diferenças entre os valores médios quantificados, que pode estar associado ao enriquecimento da amostra com padrão de P. Todavia, todos os métodos apresentaram boa reprodutibilidade, podendo ser usada tanto em amostras com baixas e altas concentrações. É importante ressaltar que as quantificações foram realizadas com as respectivas curvas de calibração, fato que deve sempre ser considerado para evitar problemas de subestimação de concentração.

\section{Comparação entre os métodos}

No método 1 a digestão foi realizada em aproximadamente 2 horas, pois faz-se o uso de $50 \mathrm{~mL}$ de amostra e ácidos concentrados. Tais características dificultam o alcance do ponto de ebulição. No momento de neutralização, há maior gasto de neutralizantes e demanda mais tempo, pois as reações ácido-base de neutralização liberam calor, sendo necessário a amostra entrar em temperatura ambiente para posterior quantificação. 0 método 2 utiliza um volume menor de amostra $(25 \mathrm{~mL})$ e faz o uso de soluções em concentrações mais baixas de $\mathrm{HCl}$ e $\mathrm{K}_{2} \mathrm{~S}_{2} \mathrm{O}_{8}$ para o momento da análise. A digestão da amostra foi mais rápida do que os outros métodos, levando aproximadamente 1 hora, e não houve dificuldade para neutralização das amostras, visto que as reações ácido-base eram mais brandas. A desvantagem deste método encontra-se na não possibilidade de armazenamento da solução de $\mathrm{K}_{2} \mathrm{~S}_{2} \mathrm{O}_{8}$ pelo fato da precipitação do sal do composto, sendo necessário preparar a solução a cada novo ensaio. Em relação ao método 3, a digestão também foi realizada em aproximadamente 2 horas, assim como houve uma grande utilização de reagentes na preparação da solução de $\mathrm{K}_{2} \mathrm{~S}_{2} \mathrm{O}_{8}$, o que acaba sendo desvantajoso quando se trata de um número elevado de amostras, ou quando necessita concentrá-las. Assim como para o método 2, não houve dificuldade para neutralização das amostras. Ao adicionar a solução reativa nas amostras não houve nenhuma diferença visível, o volume utilizado foi o mesmo e o tempo para o aparecimento da coloração foi relativamente igual para todos os métodos.

Na Figura 3 estão apresentados boxplots das absorbâncias obtidas para cada amostra em cada método, sendo a Figura 3a o ponto PASS_1 (Ponte BR 277), 3b o ponto PASS_2 (ponte Ferraria), 3c do ponto BA1 e $3 \mathrm{~d}$ do ponto BA3. 


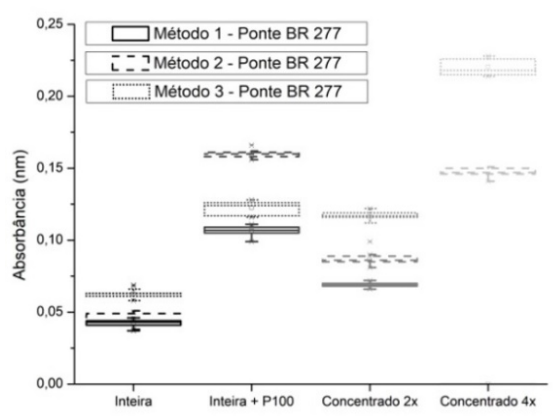

Figura 3a-Box plots do ponto PASS_1 para os métodos de digestão 1 e 2 , e as variáveis de concentração

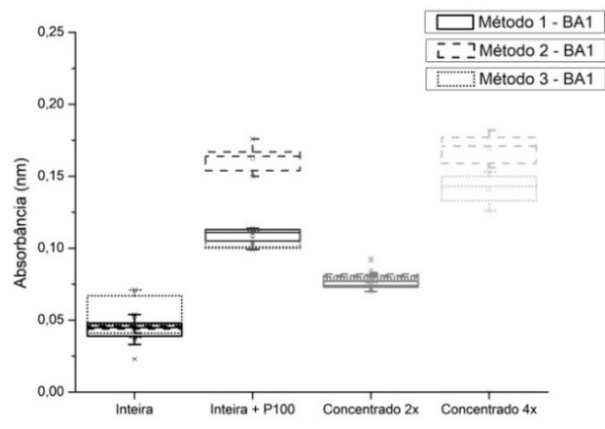

Figura 3c - Box plots do ponto BA_1 para os métodos de digestão 1 e 2 , e as variáveis de concentração

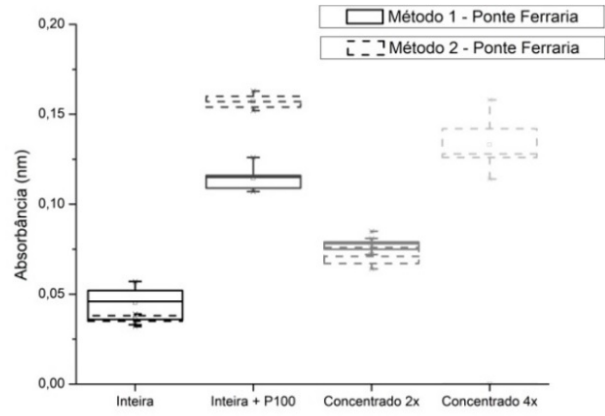

Figura 3b - Box plots do ponto PASS_2 para os métodos de digestão 1 e 2 , e as variáveis de concentração

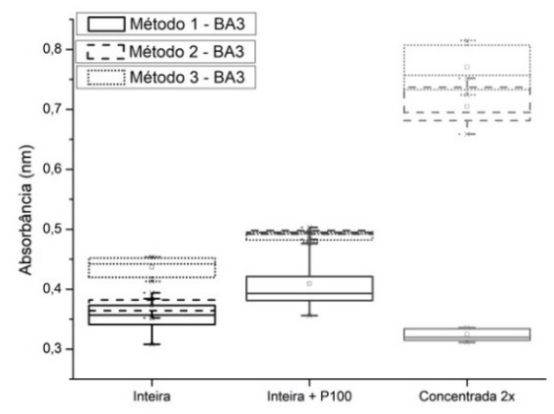

Figura 3d - Box plots do ponto BA_3 para os métodos de digestão 1 e 2 , e as variáveis de concentração

FIGURA 3 - Box-plots das amostras quantificadas para os diferentes métodos e variáveis analíticas FIGURE 3 - Box-plots of samples quantified by the distinct method and analytical variables

Nas Figuras 3a, 3b, 3c e 3d, é possível observar que os valores quantificados apresentaram baixa dispersão, devido aos box-plots com pouca espessura. Para as amostras do ponto PASS_2, o método 2 apresentou dispersão e quantificação semelhante, indicando que a reprodução do método encaixou de forma adequada para diferentes estratégias de quantificação de $\mathrm{P}$, exceto pela variável $\mathrm{A}_{4 \mathrm{x}}$ que apresentou uma leve dispersão, que pode ter sido ocasionada por algum valor de quantificação inadequado no momento de leitura. Contudo, o método 1 não variou em relação a dispersão dos valores calculados e os valores médios encontrados, mas apresenta valores extremos, que distanciam-se do valor médio. Do mesmo modo, o método 2 mostrou-se mais estável para a quantificação de P das amostras do ponto PASS_1, pois a média dos valores calculados foi similar. Isto pode estar relacionado com a menor quantidade de reagentes puros utilizados, causando menor interferência na amostra.

Observando o ponto BA1, percebe-se que há pouca diferença entre os métodos, entretanto, o método 2 apresenta a melhor dispersão de valores e o que possui menor valores atípicos quando em comparação aos demais métodos, mesmo havendo uma leve variação da média de valores quando se trata da variável Ap. Mesmo havendo pouca diferença entre os métodos para o ponto BA3, o que apresenta melhor distribuição das quantificações foi o método 2, pois observa-se que o método 1 apresenta valores extremos (distantes da média de valores obtidos) e o método 3 variou em relação aos valores médios encontrados.

Portanto, na comparação entre os métodos estudados, o método 2 mostrou-se o mais robusto, com menor dispersão de dados, representativa curva de calibração e melhor reprodução dos dados independente da amostra e/ou variável aplicada. Além disso, este método traz vantagem de possuir menor tempo de preparo, em relação aos outros métodos e uso de menos reagentes concentrados.

Adicionalmente, percebeu-se a falta de trabalhos voltados aos diferentes métodos de quantificação de fósforo em amostras de água, as dificuldades vistas diariamente, bem como os critérios para assegurar a qualidade da informação gerada. Assim, reconhece-se a necessidade de métodos analíticos eficazes que possam quantificar amostras com baixas concentrações de analito de 
maneira precisa e exata, obtendo-se resultados satisfatórios e confiáveis. No estudo de Dayton et al. (2017) buscou-se a quantificação de fósforo total em amostras sólidas através do melhor método entre três selecionados. Nesse estudo, o que obteve o melhor resultado foi o método em que utiliza o persulfato ácido, com uma recuperação de 96,6\%.

\section{Comparação entre as variáveis de amostra analisadas}

Se tratando da melhor variável analisada nas metodologias aplicadas, pode-se dizer que foi a amostra inteira se mostrou a melhor condição de análise. Pelo fato de não utilizar padrão na amostra ("enriquecimento") e não utilizar uma grande quantidade de amostra quando comparado ao teste com concentração da amostra, o que poderia ser inviável se tratando de amostras que necessitem de uma concentração maior que quatro vezes. A concentração da amostra afeta o processo da digestão, que por ser um volume maior, leva um maior tempo de digestão em comparação às amostras não concentradas e utilização de maiores quantidades de reagentes, contudo mostra-se eficaz na reprodutibilidade dos resultados e passível de utilização quando se fizer necessário.

\section{Aplicação na Gestão de Recursos Hídricos}

A adequada quantificação de $\mathrm{P}$ no ambiente aquático mostra-se de suma importância, pois pode acarretar em equivocadas tomadas de decisões para a gestão de recursos hídricos. Observando os valores obtidos para a amostra inteira nos pontos BA1, PASS_1 e PASS_2, que apresentam baixas concentrações, o uso inadequado da curva de calibração pode causar a sub-quantificação da concentração de $\mathrm{P}$ em cerca de $70 \%$, como destacado na Tabela 5. Além disso, a amostra do ponto PASS_1, se quantificada na curva de altas concentrações teria um valor negativo de concentração, o qual não é possível. Geralmente, tais quantificações negativas são atribuídas à concentração abaixo dos limites de detecção ou quantificação ou, até mesmo, a não ocorrência deste elemento no meio, caso que não se caracteriza como verdadeiro, visto que a quantificação na curva adequada apresenta concentrações e réplicas válidas.

TABELA 5 - Comparação entre o uso da curva de calibração alta e baixa para a quantificação de concentrações baixas de $P$.

TABLE 5 - Comparision between the use of high and low calibration curve for the phosphorus quantification in low concentration

\begin{tabular}{c|c|c|c}
\hline \multirow{2}{*}{ Amostra Inteira } & \multicolumn{1}{c}{$\begin{array}{c}\text { P medido na curva de } \\
\text { baixa concentração - } \\
\text { adequado (mg.L-1) }\end{array}$} & $\begin{array}{c}\text { P medido na curva de } \\
\text { alta concentração - } \\
\text { inadequado (mg.L-1) }\end{array}$ & Diferenças \\
\hline BA1 & 0,06 & 0,02 & $70 \%$ \\
\hline PASS_1 & 0,04 & $-0,001$ & erro de quantificação \\
\hline PASS_2 & 0,06 & 0,02 & $71 \%$ \\
\hline
\end{tabular}

Outra situação envolve a classificação dos corpos hídricos em classes. Tendo como análise ilustrativa o ponto PASS_2 que se classifica como ambiente lêntico por estar localizado na entrada do reservatório Passaúna. Para esta condição, a Resolução CONAMA N 357/2005, estabelece os limites de $\mathrm{P}$ total nas concentrações de $0,02 \mathrm{mg} . \mathrm{L}^{-1}$ para classe $1,0,03 \mathrm{mg} . \mathrm{L}^{-1}$ para classe 2 e $0,05 \mathrm{mg} . \mathrm{L}^{-1}$ para classe 3 e 4 . Assim, utilizando a curva de quantificação adequada para as baixas concentrações, este corpo hídrico estaria ultrapassando o limite previsto para a classe 3 e 4 . Contudo, na forma inadequada de mensuração, o corpo hídrico estaria se enquadrando na classe 1, a qual qualifica o uso desta água para abastecimento público. Portanto, ressalta-se a importância do cuidado analítico para a quantificação dos parâmetros de qualidade da água, em especial do nutriente P. 0 uso incorreto da curva de calibração pode causar a sub-quantificação de concentrações e classificações inadequadas de corpos hídricos, por exemplo.

Ademais, a escolha do método mais robusto também é importante para que a quantificação seja mais exata e representativa possível. A amostra pode apresentar características peculiares, como elevado $\mathrm{pH}$ (principalmente na presença do elemento $\mathrm{Ca}$ ), situação na qual se faz necessária o uso do método analítico mais ácido, (como o método 1 apresentado) para a adequada disponibilização do $\mathrm{P}$ na solução. A determinação analítica confiável, com representativa curva de calibração é um critério 
essencial para a segurança do dado gerado. É válido ressaltar que determinações analíticas são confiáveis dentro do intervalo determinado da curva padrão, ou seja, uma amostra de alta concentraçãs não deve ser quantificada a partir de uma curva de calibração de baixas concentrações, pois o extrapolamento de dados analíticos não, necessariamente, é linear (como observado pelos diferentes coeficientes angular).

\section{CONCLUSÕES}

A escolha do método analítico adequado deve atender a algumas estratégias de manipulação e quantificação de uma amostra ambiental, a fim de assegurar a qualidade da informação gerada e minimizar erros. Essas estratégias a serem analisadas seriam limite de detecção, faixa linear, seletividade, precisão e exatidão, juntamente com as restrições de tempo e custo. Assim com base nisso e entre os parâmetros analisados durante as metodologias desenvolvidas para a quantificação de uma amostra em laboratório, procura-se aquela que seja eficaz, mas que também poupe tempo e evite excesso de geração de efluentes químicos. Assim, após a realização de cada método pode-se observar diferenças consideráveis entre um procedimento e outro. Essas diferenças são importantes, pois nos leva ao aperfeiçoamento do trabalho, melhorando também a utilização do tempo e recursos.

Ao examinar os valores e comparações feitas entre os métodos e as variáveis, pode-se refletir em qual seria o melhor método analítico a ser aplicado. Mesmo sabendo que um método está sujeito a erros que não se pode mensurar, como o erro aleatório, que pode afetar a precisão e reprodutibilidade dos resultados, deve-se optar por aquele que apresente a menor faixa de erro e melhores condições analíticas. Portanto, com relação aos métodos avaliados, para as diferentes matrizes, o método 2 apresentou resultados satisfatórios, devido: (i) menor volume de reagentes e de amostras utilizados, (ii) tempo de digestão da amostra, e (iii) os resultados obtidos, apresentando boa precisão e reprodutibilidade e indicando menor variação de valores em relação aos outros métodos.

Se tratando da melhor variável analisada nas metodologias aplicadas, pode-se concluir que utilizar a amostra inteira se mostrou a melhor condição de análise, o que não foi observado quando utilizado padrão para enriquecimento da amostra. Amostras que demandam concentrações de volumes maiores que quatro vezes podem inviabilizar o planejamento analítico, pois demanda maior tempo de digestão em comparação às amostras não concentradas e, consequentemente, utilização de maiores quantidades de reagentes.

Em relação ao uso do método certo aplicado na curva de calibração correta também é de suma importância. No caso da utilização de curvas analítica inadequada pode haver desvios consideráveis dos resultados obtidos, como a sub-quantificação de concentrações. Isto pode ocasionar a equivocada tomada de decisão, como o uso de água sem qualidade adequada para os devidos fins, e, portanto problemas para a gestão dos recursos hídricos.

\section{AGRADECIMENTOS}

Os autores agradecem ao Conselho Nacional de Desenvolvimento Científico e Tecnológico (CNPq) e a Coordenação de Aperfeiçoamento de Pessoal de Nível Superior (CAPES) pelo auxílio financeiro.

\section{REFERÊNCIAS}

American Public Health Association - APHA. (2012). Standard Methods for the Examination of Water and Wastewater (Vol. 10, E. W. Rice, Ed.). Washington, DC: American Public Health Association.

Araucária. Prefeitura de Araucária. Dados Gerais. Recuperado em 10 de junho de 2018, de http://www.araucaria.pr.gov.br/

Brasil. Conselho Nacional do Meio Ambiente-CONAMA. (2005, 17 de março). Resolução no 357, de 17 de março de 2005. Dispõe sobre a classificação dos corpos de água e diretrizes ambientais para o seu enquadramento, bem como estabelece as condições e padrões de lançamento de efluentes, e dá outras providências. Diário Oficial [da] República Federativa do Brasil, Brasília. Recuperado em 18 de janeiro de 2018, de www.mma.gov.br/port/conama/res/res05/res35705.pdf

Coquemala V. (2005). Variação anual do fitoplâncton no Reservatório Passaúna, Paraná (Dissertação de mestrado). Setor de Ciências Biológicas, Universidade Federal do Paraná, Curitiba. 
Dayton, E. A., Whitacre, S. \& Holloman, C. (2017). Comparison of three persulfate digestion methods for total phosphorus analysis and estimation of suspended sediments. Applied Geochemistry, 78, 357-362.

Froehner, S., \& Martins, R. F. (2008). Avaliação da composição química de sedimentos do Rio Barigüi na região metropolitana de Curitiba. Quimica Nova, 31(8), 2020-2026.

Girard, J. E. \& Oliveira, M. J. (2013). Princípios de Química Ambiental (2. ed.). Rio de Janeiro: LTC.

Paraná. Secretaria de Estado do Meio Ambiente e Recursos Hídricos. Superintendência de Desenvolvimento de Recursos Hídricos e Saneamento Ambiental - SUDERHSA. (2000). Sistema de Informação Geográfica para a Gestão de Recursos Hídricos: Mapeamento do estado do Paraná. Retrieved in 2019, October 26, from http://www.aguasparana.pr.gov.br/pagina-79.html

Paraná. Secretaria de Estado do Meio Ambiente e Recursos Hídricos. Superintendência de Desenvolvimento de Recursos Hídricos e Saneamento Ambiental - SUDERHSA. (2002). Plano diretor de drenagem para a bacia do rio Iguaçu na região metropolitana de Curitiba, Relatório Final - Volume 4, Modelagem das linhas de inundação da bacia do rio Passaúna, Dezembro de 2002. Recuperado em 26 de janeiro 2019, de http://www.aguasparana.pr.gov.br/arquivos/File/pddrenagem/volume4/SUD0104RP_WR121_FI.pdf

Prado, L. L. (2015). Procedimento analítico para quantificação de Fósforo Total por Digestão Ácida - Adaptado de "Avaliação da composição química de sedimentos do Rio Barigui na Região Metropolitana de Curitiba", Froehner, S. e Martins, R.F. (2008) - Conversas pessoais (2015).

Quevedo, C. M. G. D., \& Paganini, W. D. S. (2011). Impactos das atividades humanas sobre a dinâmica do fósforo no meio ambiente e seus reflexos na saúde pública. Ciencia \& Saude Coletiva, 16, 3539-3539.

Skoog, D. A., West, D. M., Holler, F. J., \& Crouch, S. R. (2006). Fundamentos de Química Analítica (8. ed.). São Paulo: Cengage Learning.

Veiga B. V. (2010). Fatores intervenientes na dinâmica do fósforo em ambientes lênticos - investigação sobre o reservatório de Alagados no Estado do Paraná (Doutorado em Engenharia Civil). Escola Politécnica, Universidade de São Paulo, São Paulo.

Worsfold, P., McKelvie, I., \& Monbet, P. (2016). Determination of phosphorus in natural waters: a historical review. Analytica Chimica Acta, 918, 8-20.

\section{Contribuição dos autores:}

Fernanda Batista Guimarães Cipriano é aluna de graduação em química da Universidade Federal do Paraná (UFPR), e foi aluna bolsista CNPq de Iniciação Científica no PPG em Engenharia de Recursos Hídricos e Ambiental (PPGERHA). Ela foi responsável por toda execução do trabalho em laboratório, processamento e análise dos dados, bem como a elaboração deste texto.

Caroline Kozak é aluna de doutorado do PPGERHA da UFPR. Ela foi responsável pela co-orientação e supervisão do desenvolvimento deste trabalho, auxiliando nas atividades de campo para coleta de amostras, auxílio no laboratório, processamento e análise dos dados e elaboração deste texto.

Luciane Lemos do Prado é técnica em química ambiental pela Universidade Tecnológica Federal do Paraná e coordenadora do Laboratório de Engenharia Ambiental Francisco Borsari Neto. Ela foi responsável pela elaboração do planejamento experimental deste trabalho, bem como auxílio no laboratório, processamento de dados e elaboração deste texto.

Cristovão Vicente Scapulatempo Fernandes é professor titular da UFPR no Departamento de Hidráulica e Saneamento. Ele foi o professor orientador deste trabalho, auxiliando na viabilidade de espaço e recursos, planejamento experimental, atividades de campo para coleta das amostras e elaboração deste texto. 


\section{MATERIAL COMPLEMENTAR}

Este arquivo contem todos os dados gerados e processados para a consolidação da rotina analítica da digestão ácida proposto pelo método 1 e 3, de acordo com Apha (2012), bem como o método 2 proposto por Prado (2015). É importante ressaltar que cada ponto das curvas de calibração foi realizado em triplicata, e posteriormente foram retiradas 5 alíquotas para quantificação pelo método do ácido ascórbico (Apha, 2012), totalizando 15 réplicas para cada ponto. As amostras foram processadas respeitando a mesma quantidade de réplicas. Valores que estão identificados em negrito representam os valores retirados dos cálculos por apresentarem inconsistência analítica observada pelos autores

Os dados são apresentados da seguinte forma:

\section{Método 1}

1.1. Baixas concentrações

1.2. Altas concentrações

1.3. Amostras ponto BA1

1.4. Amostras ponto BA2

1.5. Amostras ponto PASS_1

1.6. Amostras ponto PASS_2

\section{Método 2}

2.1. Baixas concentrações

2.2. Altas concentrações

2.3. Amostras ponto BA1

2.4. Amostras ponto BA2

2.5. Amostras ponto PASS_1

2.6. Amostras ponto PASS_2

3. Método 3

3.1. Baixas concentrações

3.2. Altas concentrações

3.3. Amostras ponto BA1

3.4. Amostras ponto BA2

3.5. Amostras ponto PASS_2

\section{MÉTODO 1}

1.1. Baixas concentrações

TABELA C1 - Curva de calibração para as concentrações baixas, réplica número 1, 2 e 3, método 1.

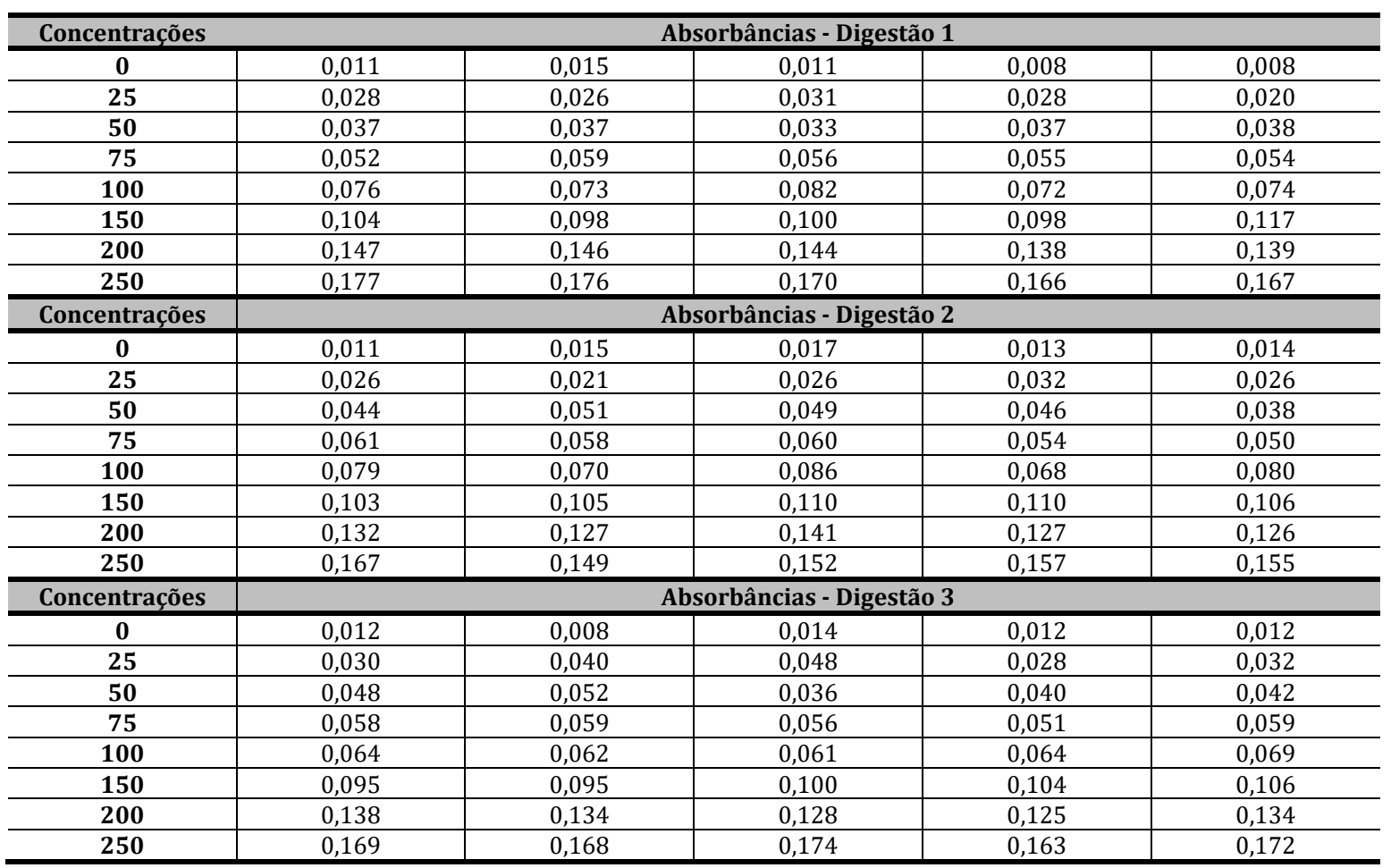




\section{Curva de Calibração - Concentração Baixa}

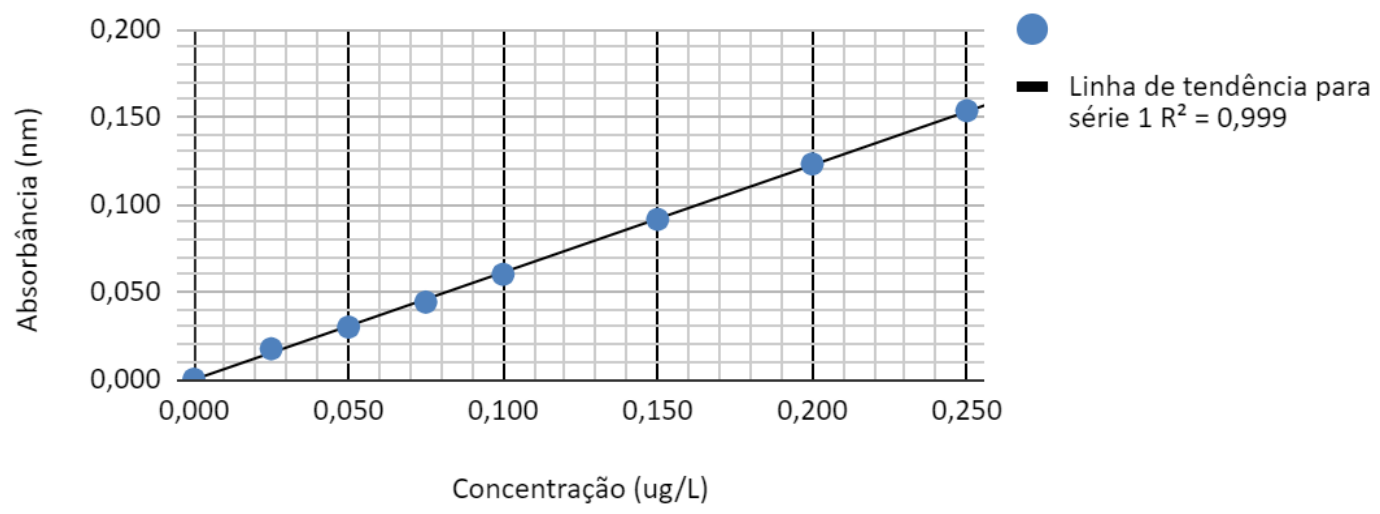

FIGURA C1 - Curva de calibração para concentrações baixas com os valores médios obtidos das três digestões, método 1.

\subsection{Altas concentrações}

TABELA C2 - Curva de calibração para as concentrações altas, réplica número 1, 2 e 3, método 1

\begin{tabular}{|c|c|c|c|c|c|}
\hline Concentrações & \multicolumn{5}{|c|}{ Absorbâncias - Digestão 1} \\
\hline $\mathbf{0}$ & 0,012 & 0,009 & 0,014 & 0,011 & 0,012 \\
\hline 100 & 0,067 & 0,067 & 0,067 & 0,072 & 0,070 \\
\hline 300 & 0,179 & 0,177 & 0,175 & 0,174 & 0,178 \\
\hline 400 & 0,243 & 0,245 & 0,239 & 0,238 & 0,232 \\
\hline 500 & 0,281 & 0,281 & 0,264 & 0,266 & 0,266 \\
\hline 700 & 0,427 & 0,423 & 0,426 & 0,427 & 0,428 \\
\hline 900 & 0,457 & 0,455 & 0,388 & 0,391 & 0,396 \\
\hline 1500 & 0,745 & 0,736 & 0,657 & 0,659 & 0,657 \\
\hline Concentrações & \multicolumn{5}{|c|}{ Absorbâncias - Digestão 2} \\
\hline $\mathbf{0}$ & 0,010 & 0,010 & 0,012 & 0,009 & 0,008 \\
\hline 100 & 0,068 & 0,069 & 0,072 & 0,068 & 0,072 \\
\hline 300 & 0,178 & 0,182 & 0,171 & 0,178 & 0,177 \\
\hline 400 & 0,258 & 0,251 & 0,246 & 0,247 & 0,253 \\
\hline 500 & 0,302 & 0,310 & 0,304 & 0,306 & 0,306 \\
\hline 700 & 0,036 & 0,338 & 0,304 & 0,344 & 0,344 \\
\hline 900 & 0,333 & 0,342 & 0,338 & 0,333 & 0,341 \\
\hline 1500 & 0,609 & 0,623 & 0,621 & 0,623 & 0,612 \\
\hline Concentrações & \multicolumn{5}{|c|}{ Absorbâncias - Digestão 3} \\
\hline $\mathbf{0}$ & 0,008 & 0,015 & 0,016 & 0,012 & 0,014 \\
\hline 100 & 0,074 & 0,070 & 0,074 & 0,070 & 0,076 \\
\hline 300 & 0,179 & 0,181 & 0,184 & 0,188 & 0,185 \\
\hline 400 & 0,211 & 0,217 & 0,222 & 0,217 & 0,215 \\
\hline 500 & 0,266 & 0,264 & 0,272 & 0,264 & 0,269 \\
\hline 700 & 0,300 & 0,301 & 0,299 & 0,285 & 0,285 \\
\hline 900 & 0,348 & 0,365 & 0,349 & 0,336 & 0,339 \\
\hline 1500 & 0,610 & 0,604 & 0,595 & 0,610 & 0,615 \\
\hline
\end{tabular}




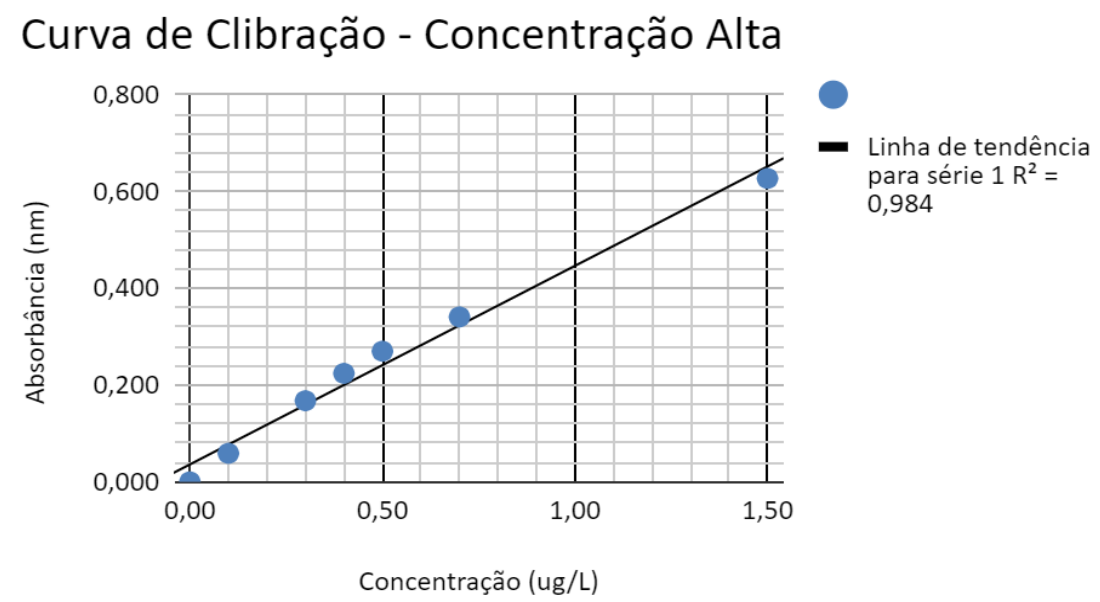

FIGURA C2 - Curva de calibração para concentrações altas com os valores médios obtidos das três digestões.

1.3. Amostras ponto BA1

TABELA C3 - Absorbâncias obtidas para a amostra do BA1, do Rio Barigui, réplica número 1, 2 e 3, método 1

\begin{tabular}{|c|c|c|c|c|c|}
\hline \multicolumn{3}{|c|}{$\overline{\text { BA } 1}$} & \multicolumn{3}{|c|}{ Absorbância - Digestão 1} \\
\hline $\mathbf{A}_{I}$ & 0,074 & 0,046 & 0,049 & 0,053 & 0,045 \\
\hline $\mathbf{A P}$ & 0,109 & 0,113 & 0,113 & 0,107 & 0,112 \\
\hline $\mathbf{A}_{2 \mathrm{x}}$ & 0,132 & 0,100 & 0,073 & 0,074 & 0,073 \\
\hline $\mathbf{A}_{4 x}$ & 0,243 & 0,241 & 0,248 & 0,232 & 0,248 \\
\hline \multicolumn{3}{|c|}{ BA 1} & \multicolumn{3}{|c|}{ Absorbância - Digestão 2} \\
\hline $\mathbf{A}_{\mathrm{I}}$ & 0,045 & 0,038 & 0,054 & - & 0,047 \\
\hline $\mathbf{A}_{\mathbf{P}}$ & 0,107 & 0,102 & 0,099 & - & 0,112 \\
\hline $\mathbf{A}_{2 \mathrm{x}}$ & 0,076 & 0,073 & 0,077 & - & 0,091 \\
\hline $\mathbf{A}_{4 \mathrm{x}}$ & 0,234 & 0,254 & 0,237 & - & 0,242 \\
\hline \multicolumn{3}{|c|}{ BA 1} & \multicolumn{3}{|c|}{ Absorbância - Digestão 3} \\
\hline $\mathbf{A}_{\mathrm{I}}$ & 0,042 & 0,033 & 0,044 & 0,023 & 0,039 \\
\hline $\mathbf{A P}$ & 0,105 & 0,099 & 0,114 & 0,111 & 0,112 \\
\hline $\mathbf{A}_{2 \mathrm{x}}$ & 0,073 & 0,081 & 0,079 & 0,070 & 0,075 \\
\hline $\mathbf{A}_{4 \mathrm{x}}$ & 0,247 & 0,242 & 0,252 & 0,237 & 1,000 \\
\hline
\end{tabular}

Nota: $A_{I}=$ Amostra inteira. $A_{P}=$ Amostra com adição do padrão de $100 \mathrm{mg} \mathrm{L}^{-1}$ de $P . A_{2 x}=$ Amostra concentrada 2 vezes. $A_{4 x}=$ Amostra concentrada 4 vezes

1.4. Amostras ponto BA3

TABELA C4 - Absorbâncias obtidas para a amostra do BA3, do Rio Barigui, réplica número 1, 2 e 3, método 1

\begin{tabular}{c|c|c|c|c|c}
\hline \multicolumn{3}{|c|}{ BA 3 } & \multicolumn{3}{c}{ Absorbância - Digestão 1 } \\
\hline $\mathbf{A}_{\mathbf{I}}$ & 0,370 & 0,365 & 0,376 & 0,373 & 0,365 \\
\hline $\mathbf{A}_{\mathbf{P}}$ & $\mathbf{0 , 5 0 7}$ & $\mathbf{0 , 5 8 8}$ & $\mathbf{0 , 5 5 0}$ & 0,397 & 0,421 \\
\hline $\mathbf{A}_{\mathbf{2 x}}$ & $\mathbf{0 , 3 8 2}$ & 0,333 & 0,335 & 0,336 & 0,334 \\
\hline \multicolumn{3}{|c|}{ BA 3 } & \multicolumn{3}{c}{ Absorbância - Digestão 3 } \\
\hline $\mathbf{A}_{\mathbf{I}}$ & 0,357 & 0,312 & 0,308 & - & 0,341 \\
\hline $\mathbf{A}_{\mathbf{P}}$ & 0,359 & 0,392 & 0,356 & - & 0,381 \\
\hline $\mathbf{A}_{\mathbf{2 x}}$ & 0,329 & 0,319 & 0,333 & - & 0,311 \\
\hline $\mathbf{A}_{\mathbf{I}}$ & $\mathbf{B A} 3$ & \multicolumn{3}{|c}{ Absorbância - Digestão 3 } \\
\hline $\mathbf{A}_{\mathbf{P}}$ & 0,384 & 0,347 & 0,342 & $\mathbf{0 , 4 3 4}$ & $\mathbf{0 , 4 3 1}$ \\
\hline $\mathbf{A}_{\mathbf{2 x}}$ & 0,473 & 0,392 & 0,394 & 0,476 & 0,475 \\
\hline
\end{tabular}

Nota: $A_{I}=$ Amostra inteira. $A_{P}=$ Amostra com adição do padrão de $100 \mathrm{mg} \mathrm{L}^{-1}$ de $P . A_{2 x}=$ Amostra concentrada 2 vezes.

1.5. Amostras ponto PASS_1 
TABELA C5 - Absorbâncias obtidas para a amostra do PASS_1, do Rio Passaúna, réplica número 1, 2 e 3, método 1

\begin{tabular}{|c|c|c|c|c|c|}
\hline \multicolumn{3}{|c|}{ PASS_1 } & \multicolumn{3}{|c|}{ Absorbância - Digestão 1} \\
\hline $\mathbf{A}_{I}$ & 0,041 & 0,041 & 0,046 & 0,050 & 0,043 \\
\hline AP & 0,203 & 0,111 & 0,099 & 0,109 & 0,104 \\
\hline $\mathbf{A}_{2 \mathrm{x}}$ & 0,068 & 0,072 & 0,071 & 0,069 & - \\
\hline \multicolumn{3}{|c|}{ PASS_1 } & \multicolumn{3}{|c|}{ Absorbância - Digestão 2} \\
\hline $\mathbf{A}_{I}$ & 0,044 & 0,043 & 0,043 & - & 0,043 \\
\hline $\mathbf{A}_{\mathbf{P}}$ & 0,107 & 0,111 & 0,109 & - & 0,110 \\
\hline $\mathbf{A}_{2 \mathrm{x}}$ & 0,069 & 0,070 & 0,068 & - & 0,066 \\
\hline \multicolumn{3}{|c|}{ PASS_1 } & \multicolumn{3}{|c|}{ Absorbância - Digestão 3} \\
\hline $\mathbf{A}_{\mathrm{I}}$ & 0,041 & 0,045 & 0,037 & 0,041 & 0,040 \\
\hline $\mathbf{A}_{\mathbf{P}}$ & 0,105 & 0,109 & 0,102 & 0,105 & 0,105 \\
\hline $\mathbf{A}_{2 \mathrm{x}}$ & - & - & - & - & 0,199 \\
\hline
\end{tabular}

Nota: $A_{I}=$ Amostra inteira. $A_{P}=$ Amostra com adição do padrão de $100 \mathrm{mg} \mathrm{L}^{-1}$ de $P$. $A_{2 x}=$ Amostra concentrada 2 vezes

1.6. Amostras ponto PASS_2

TABELA C6 - Absorbâncias obtidas para a amostra do PASS_2, do Rio Passaúna, réplica número 1, 2 e 3, método 1

\begin{tabular}{c|c|c|c|c|c}
\hline \multicolumn{3}{|c|}{ PASS_2 } & \multicolumn{3}{c}{ Absorbância - Digestão 1 } \\
\hline $\mathbf{A}_{\mathbf{I}}$ & 0,033 & 0,036 & 0,035 & 0,036 & 0,035 \\
\hline $\mathbf{A}_{\mathbf{P}}$ & 0,113 & 0,115 & 0,116 & 0,120 & 0,115 \\
\hline $\mathbf{A}_{\mathbf{2 x}}$ & 0,075 & 0,076 & 0,081 & 0,072 & 0,076 \\
\hline \multicolumn{7}{|c|}{ PASS_2 } & \multicolumn{3}{|c}{ Absorbância - Digestão 2 } \\
\hline $\mathbf{A}_{\mathbf{I}}$ & 0,056 & 0,057 & 0,052 & - & 0,046 \\
\hline $\mathbf{A}_{\mathbf{P}}$ & 0,109 & 0,107 & 0,108 & - & 0,109 \\
\hline $\mathbf{A}_{\mathbf{2 x}}$ & 0,079 & 0,079 & 0,078 & - & 0,079 \\
\hline $\mathbf{A}_{\mathbf{I}}$ & PASS_2 & & \multicolumn{3}{c}{ Absorbância - Digestão 3 } \\
\hline $\mathbf{A}_{\mathbf{P}}$ & 0,055 & 0,052 & 0,050 & $\mathbf{0 , 3 9 0}$ & $\mathbf{0 , 0 7 7}$ \\
\hline $\mathbf{A}_{\mathbf{2 x}}$ & 0,116 & 0,121 & $\mathbf{0 , 1 3 3}$ & $\mathbf{0 , 1 3 0}$ & $\mathbf{0 , 1 7 8}$ \\
\hline
\end{tabular}

Nota: $A_{I}=$ Amostra inteira. $A_{P}=$ Amostra com adição do padrão de $100 \mathrm{mg} \mathrm{L}^{-1}$ de $\mathrm{P} . \mathrm{A}_{2 \mathrm{x}}=$ Amostra concentrada 2 vezes.

\section{MÉTODO 2}

2.1. Baixas concentrações

TABELA C7 - Curva de calibração para as concentrações baixas, réplica número 1, 2 e 3, método 2.

\begin{tabular}{|c|c|c|c|c|c|}
\hline Concentrações & \multicolumn{5}{|c|}{ Absorbâncias - Digestão 1} \\
\hline $\mathbf{0}$ & 0,017 & 0,009 & 0,009 & 0,009 & 0,016 \\
\hline 25 & 0,025 & 0,025 & 0,029 & 0,029 & 0,026 \\
\hline 50 & 0,038 & 0,035 & 0,041 & 0,043 & 0,040 \\
\hline 75 & 0,055 & 0,059 & 0,060 & 0,059 & 0,055 \\
\hline 100 & 0,069 & 0,068 & 0,075 & 0,084 & 0,100 \\
\hline 150 & 0,097 & 0,101 & 0,099 & 0,099 & 0,087 \\
\hline Concentrações & \multicolumn{5}{|c|}{ Absorbâncias - Digestão 2} \\
\hline $\mathbf{0}$ & 0,015 & 0,014 & 0,014 & 0,015 & 0,014 \\
\hline 25 & 0,029 & 0,030 & 0,028 & 0,030 & 0,034 \\
\hline 50 & 0,046 & 0,048 & 0,041 & 0,047 & 0,048 \\
\hline 75 & 0,506 & 0,063 & 0,054 & 0,057 & 0,055 \\
\hline Concentrações & \multicolumn{5}{|c|}{ Absorbâncias - Digestão 3} \\
\hline $\mathbf{0}$ & 0,029 & 0,027 & 0,031 & 0,029 & 0,030 \\
\hline 25 & 0,038 & 0,032 & 0,036 & 0,034 & 0,034 \\
\hline 50 & 0,381 & 0,040 & 0,045 & 0,037 & 0,047 \\
\hline 75 & 0,057 & 0,056 & 0,057 & 0,057 & 0,056 \\
\hline 100 & 0,073 & 0,073 & 0,065 & 0,076 & 0,071 \\
\hline 150 & 0,100 & 0,095 & 0,115 & 0,102 & 0,103 \\
\hline 200 & 0,729 & 0,124 & 0,127 & 0,126 & 0,130 \\
\hline 250 & 0,151 & 0,151 & 0,153 & 0,161 & 0,162 \\
\hline
\end{tabular}




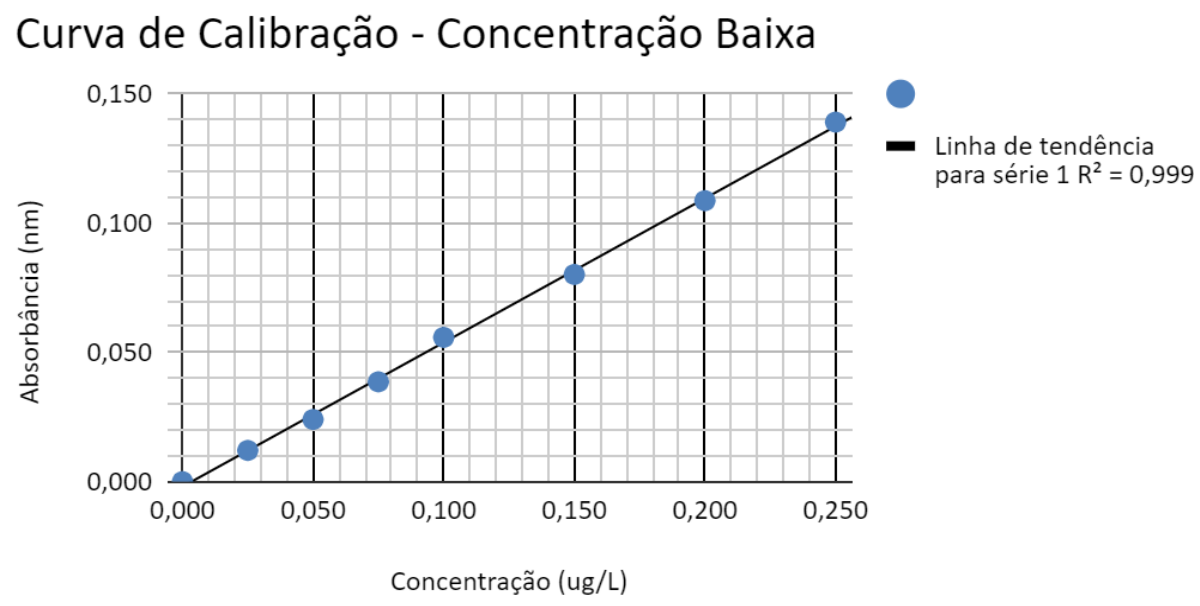

FIGURA C3 - Curva de calibração para concentrações baixas com os valores médios obtidos das três digestões, método 2.

\subsection{Altas concentrações}

TABELA C8 - Curva de calibração para as concentrações altas, réplica número 1, 2 e 3, método 2.

\begin{tabular}{|c|c|c|c|c|c|}
\hline Concentrações & \multicolumn{5}{|c|}{ Absorbâncias - Digestão 1} \\
\hline $\mathbf{0}$ & 0,010 & 0,014 & 0,014 & 0,012 & 0,013 \\
\hline 100 & 0,072 & 0,071 & 0,071 & 0,073 & 0,074 \\
\hline 300 & 0,192 & 0,185 & 0,192 & 0,189 & 0,197 \\
\hline 400 & 0,243 & 0,253 & 0,252 & 0,250 & 0,244 \\
\hline 500 & 0,307 & 0,310 & 0,302 & 0,314 & 0,313 \\
\hline 700 & 0,428 & 0,425 & 0,428 & 0,427 & 0,427 \\
\hline 900 & 0,552 & 0,558 & 0,537 & 0,555 & 0,547 \\
\hline 1500 & 0,771 & 0,754 & 0,790 & 0,775 & 0,787 \\
\hline Concentrações & \multicolumn{5}{|c|}{ Absorbâncias - Digestão 2} \\
\hline $\mathbf{0}$ & 0,011 & 0,014 & 0,011 & 0,014 & 0,012 \\
\hline 100 & 0,071 & 0,064 & 0,071 & 0,074 & 0,069 \\
\hline 300 & 0,186 & 0,185 & 0,190 & 0,189 & 0,195 \\
\hline 400 & 0,243 & 0,253 & 0,253 & 0,251 & 0,247 \\
\hline 500 & 0,310 & 0,305 & 0,309 & 0,310 & 0,310 \\
\hline 700 & 0,428 & 0,424 & 0,430 & 0,421 & 0,429 \\
\hline 900 & 0,533 & 0,525 & 0,536 & 0,541 & 0,536 \\
\hline 1500 & 0,794 & 0,781 & 0,793 & 0,788 & 0,833 \\
\hline Concentrações & \multicolumn{5}{|c|}{ Absorbâncias - Digestão 3} \\
\hline $\mathbf{0}$ & 0,010 & 0,011 & 0,010 & 0,011 & 0,024 \\
\hline 100 & 0,069 & 0,073 & 0,076 & 0,072 & 0,072 \\
\hline 300 & 0,190 & 0,188 & 0,187 & 0,183 & 0,184 \\
\hline 400 & 0,250 & 0,249 & 0,248 & 0,250 & 0,251 \\
\hline 500 & 0,300 & 0,301 & 0,310 & 0,303 & 0,296 \\
\hline 700 & 0,427 & 0,424 & 0,426 & 0,426 & 0,426 \\
\hline 900 & 0,539 & 0,544 & 0,545 & 0,547 & 0,541 \\
\hline 1500 & 0,790 & 0,799 & 0,794 & 0,783 & 0,790 \\
\hline
\end{tabular}




\section{Curva de Calibração - Concentração Alta}

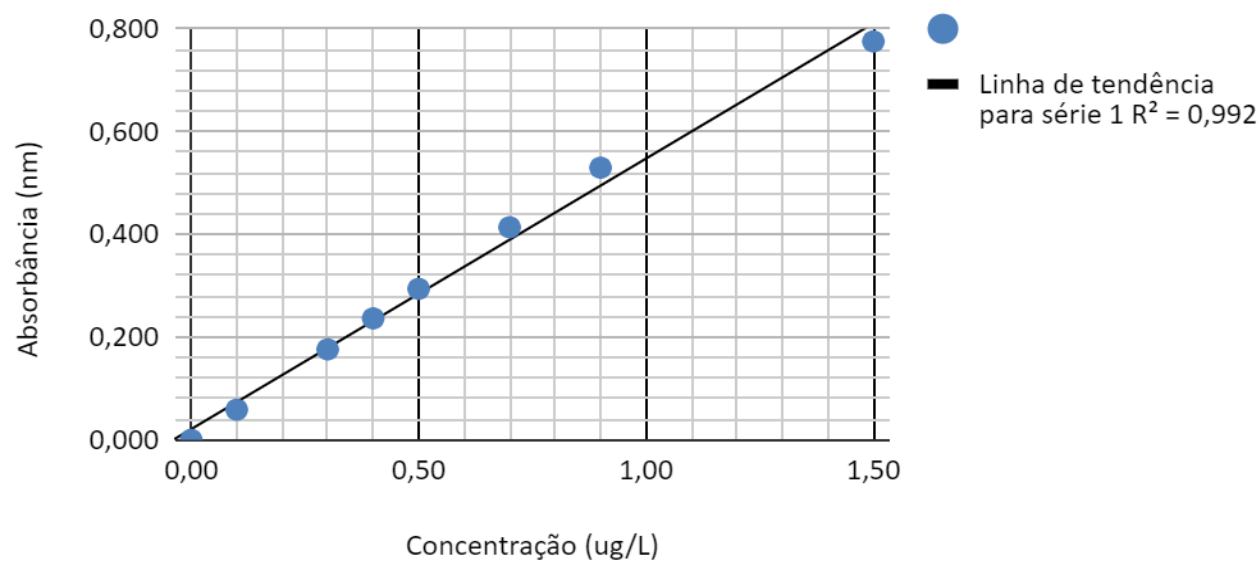

FIGURA C4 - Curva de calibração para concentrações altas com os valores médios obtidos das três digestões, método 2 .

\subsection{Amostras ponto BA1}

TABELA C9 - Absorbâncias obtidas para a amostra do BA1, do Rio Barigui, réplica número 1, 2 e 3, método 2.

\begin{tabular}{|c|c|c|c|c|c|}
\hline \multicolumn{3}{|c|}{ BA 1} & \multicolumn{3}{|c|}{ Absorbância - Digestão 1} \\
\hline $\mathbf{A}_{\mathrm{I}}$ & 0,041 & 0,044 & 0,044 & 0,044 & 0,037 \\
\hline AP & 0,150 & 0,157 & 0,154 & 0,152 & 0,153 \\
\hline$A_{2 x}$ & 0,082 & 0,082 & 0,080 & 0,082 & 0,074 \\
\hline $\mathbf{A}_{4 \mathrm{x}}$ & 0,175 & 0,177 & 0,181 & 0,178 & 0,173 \\
\hline \multicolumn{3}{|c|}{ BA 1} & \multicolumn{3}{|c|}{ Absorbância - Digestão 2} \\
\hline $\mathbf{A}_{\mathbf{I}}$ & 0,048 & 0,047 & 0,054 & 0,048 & 0,045 \\
\hline $\mathbf{A}_{\mathbf{P}}$ & 0,176 & 0,167 & 0,166 & 0,164 & 0,164 \\
\hline$A_{2 x}$ & 0,080 & 0,081 & 0,081 & 0,079 & 0,077 \\
\hline $\mathbf{A}_{4 x}$ & 0,158 & 0,159 & 0,156 & 0,162 & 0,157 \\
\hline \multicolumn{3}{|c|}{ BA 1} & \multicolumn{3}{|c|}{ Absorbância - Digestão 3} \\
\hline $\mathbf{A}_{\mathrm{I}}$ & 0,046 & 0,042 & 0,046 & 0,049 & 0,047 \\
\hline AP & 0,165 & 0,162 & 0,167 & 0,169 & 0,168 \\
\hline $\mathbf{A}_{2 \mathrm{x}}$ & 0,083 & 0,093 & 0,080 & 0,082 & 0,088 \\
\hline $\mathbf{A}_{4 x}$ & 0,168 & 0,172 & 0,171 & 0,182 & 0,171 \\
\hline
\end{tabular}

Nota: $A_{I}=$ Amostra inteira. $A_{P}=$ Amostra com adição do padrão de $100 \mathrm{mg} \mathrm{L}^{-1}$ de $P . A_{2 x}=$ Amostra concentrada 2 vezes. $A_{4 x}=$ Amostra concentrada 4 vezes

\subsection{Amostras ponto BA3}

TABELA C10 - Absorbâncias obtidas para a amostra do BA3, do Rio Barigui, réplica número 1, 2 e 3, método 2.

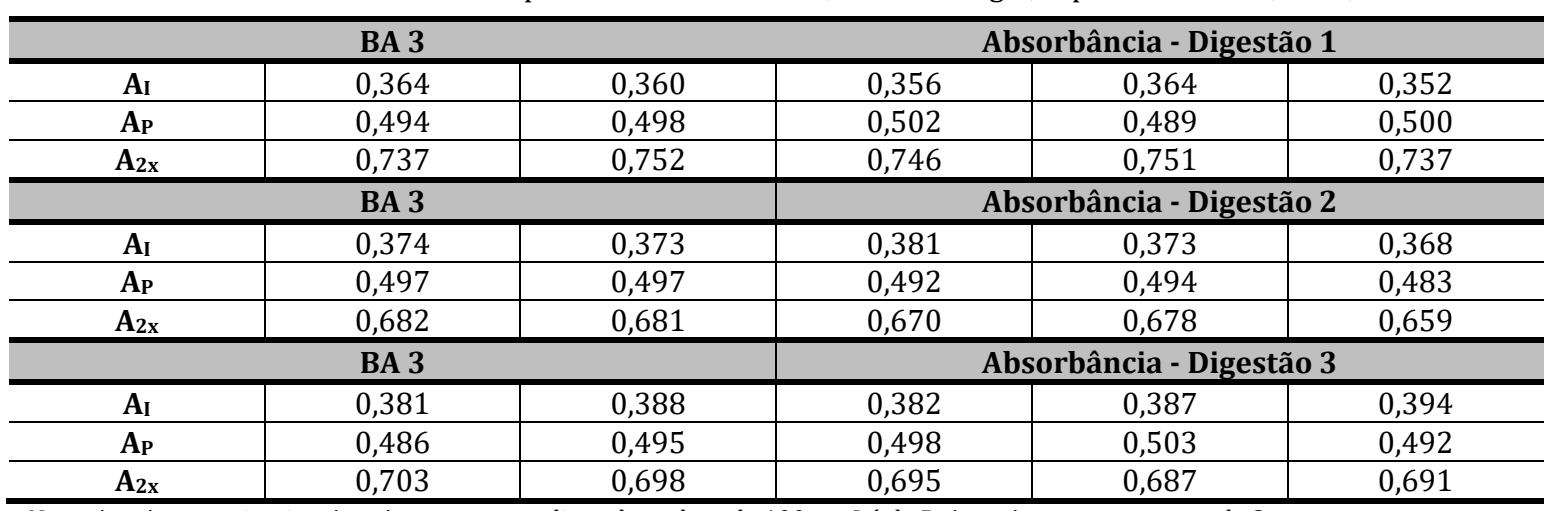

Nota: $A_{I}=$ Amostra inteira. $A_{P}=$ Amostra com adição do padrão de $100 \mathrm{mg} \mathrm{L}^{-1}$ de $P . A_{2 x}=$ Amostra concentrada 2 vezes 


\subsection{Amostras ponto PASS_1}

TABELA C11 - Absorbâncias obtidas para a amostra do PASS_1, do Rio Passaúna, réplica número 1, 2 e 3, método 2

\begin{tabular}{|c|c|c|c|c|c|}
\hline \multicolumn{3}{|c|}{ PASS_1 } & \multicolumn{3}{|c|}{ Absorbância - Digestão 1} \\
\hline $\mathbf{A}_{I}$ & 0,038 & 0,044 & 0,042 & 0,039 & 0,042 \\
\hline AP & 0,157 & 0,157 & 0,156 & 0,166 & 0,159 \\
\hline $\mathbf{A}_{2 \mathrm{x}}$ & 0,087 & 0,090 & 0,086 & 0,081 & 0,085 \\
\hline $\mathbf{A}_{4 \mathrm{x}}$ & 0,146 & 0,148 & 0,150 & 0,150 & 0,141 \\
\hline \multicolumn{3}{|c|}{ PASS_1 } & \multicolumn{3}{|c|}{ Absorbância - Digestão 2} \\
\hline $\mathbf{A}_{\mathrm{I}}$ & 0,043 & 0,043 & 0,038 & 0,043 & 0,041 \\
\hline $\mathbf{A P}_{\mathbf{P}}$ & 0,160 & 0,159 & 0,161 & 0,162 & 0,189 \\
\hline$A_{2 x}$ & 0,084 & 0,087 & 0,089 & 0,088 & 0,066 \\
\hline $\mathbf{A}_{4 \mathrm{x}}$ & 0,145 & 0,146 & 0,150 & 0,151 & 0,147 \\
\hline \multicolumn{3}{|c|}{ PASS_1 } & \multicolumn{3}{|c|}{ Absorbância - Digestão 3} \\
\hline $\mathbf{A}_{I}$ & 0,049 & 0,051 & 0,049 & 0,050 & 0,068 \\
\hline $\mathbf{A}_{\mathbf{P}}$ & 0,158 & 0,185 & 0,161 & 0,160 & 0,160 \\
\hline$A_{2 x}$ & 0,089 & 0,085 & 0,081 & 0,089 & 0,086 \\
\hline $\mathbf{A}_{4 \mathrm{x}}$ & 0,248 & 0,25 & 0,252 & 0,249 & 0,252 \\
\hline
\end{tabular}

Nota: $A_{I}=$ Amostra inteira. $A_{P}=$ Amostra com adição do padrão de $100 \mathrm{mg} \mathrm{L}^{-1}$ de $\mathrm{P} . \mathrm{A}_{2 \mathrm{x}}=$ Amostra concentrada 2 vezes. $\mathrm{A}_{4 \mathrm{x}}=$ Amostra concentrada 4 vezes

\subsection{Amostras ponto PASS_2}

TABELA C12 - Absorbâncias obtidas para a amostra do PASS_2, do Rio Passaúna, réplica número 1, 2 e 3, método 2

\begin{tabular}{|c|c|c|c|c|c|}
\hline \multicolumn{3}{|c|}{ PASS_2 } & \multicolumn{3}{|c|}{ Absorbância - Digestão 1} \\
\hline $\mathbf{A}_{I}$ & 0,032 & 0,039 & 0,037 & 0,039 & 0,034 \\
\hline AP & 0,154 & 0,154 & 0,155 & 0,160 & 0,154 \\
\hline $\mathbf{A}_{2 \mathrm{x}}$ & 0,066 & 0,103 & 0,067 & 0,064 & - \\
\hline $\mathbf{A}_{4 \mathrm{x}}$ & 0,131 & 0,129 & 0,128 & 0,13 & 0,128 \\
\hline \multicolumn{3}{|c|}{ PASS_2 } & \multicolumn{3}{|c|}{ Absorbância - Digestão 2} \\
\hline $\mathbf{A}_{I}$ & 0,038 & 0,037 & 0,038 & 0,037 & 0,035 \\
\hline $\mathbf{A}_{\mathbf{P}}$ & 0,162 & 0,152 & 0,156 & 0,154 & 0,157 \\
\hline $\mathbf{A}_{2 \mathrm{x}}$ & 0,083 & 0,076 & 0,085 & 0,076 & - \\
\hline $\mathbf{A}_{4 \mathrm{x}}$ & 0,121 & 0,126 & 0,177 & 0,123 & 0,126 \\
\hline \multicolumn{3}{|c|}{ PASS_2 } & \multicolumn{3}{|c|}{ Absorbância - Digestão 3} \\
\hline $\mathbf{A}_{\mathrm{I}}$ & 0,035 & 0,036 & 0,036 & 0,036 & 0,035 \\
\hline $\mathbf{A P}$ & 0,158 & 0,161 & 0,158 & 0,159 & 0,163 \\
\hline $\mathbf{A}_{2 \mathrm{x}}$ & 0,072 & 0,068 & 0,071 & 0,068 & 0,073 \\
\hline $\mathbf{A}_{4 \mathrm{x}}$ & 0,114 & 0,15 & 0,142 & 0,158 & 0,148 \\
\hline
\end{tabular}

Nota: $A_{I}=$ Amostra inteira. $A_{P}=$ Amostra com adição do padrão de $100 \mathrm{mg} \mathrm{L}^{-1}$ de P. $A_{2 x}=$ Amostra concentrada 2 vezes. A4x $=$ Amostra concentrada 4 vezes 


\section{MÉTODO 3}

3.1. Baixas concentrações

TABELA C13 - Curva de calibração para as concentrações baixas, réplica número 1, 2 e 3, método 3.

\begin{tabular}{|c|c|c|c|c|c|}
\hline Concentrações & \multicolumn{5}{|c|}{ Absorbância - Digestão 1} \\
\hline $\mathbf{0}$ & 0,022 & 0,022 & 0,020 & 0,088 & 0,053 \\
\hline 25 & 0,021 & 0,021 & 0,021 & 0,022 & 0,032 \\
\hline 50 & 0,039 & 0,037 & 0,038 & 0,035 & 0,035 \\
\hline 75 & 0,046 & 0,048 & 0,047 & 0,046 & 0,060 \\
\hline 100 & 0,060 & 0,061 & 0,067 & 0,069 & 0,068 \\
\hline 150 & 0,105 & 0,107 & 0,107 & 0,106 & 0,113 \\
\hline 200 & 0,134 & 0,133 & 0,131 & 0,132 & 0,132 \\
\hline 250 & 0,184 & 0,183 & 0,182 & 0,179 & 0,177 \\
\hline Concentrações & \multicolumn{5}{|c|}{ Absorbância - Digestão 2} \\
\hline $\mathbf{0}$ & 0,008 & 0,016 & 0,008 & 0,009 & 0,007 \\
\hline 25 & 0,034 & 0,035 & 0,034 & 0,037 & 0,037 \\
\hline 50 & 0,034 & 0,034 & 0,035 & 0,036 & 0,040 \\
\hline 75 & 0,050 & 0,050 & 0,050 & 0,059 & 0,074 \\
\hline 100 & 0,071 & 0,068 & 0,066 & 0,066 & 0,067 \\
\hline 150 & 0,095 & 0,095 & 0,094 & 0,091 & 0,092 \\
\hline 200 & 0,133 & 0,134 & 0,131 & 0,132 & 0,132 \\
\hline 250 & 0,162 & 0,161 & 0,161 & 0,161 & 0,163 \\
\hline Concentrações & \multicolumn{5}{|c|}{ Absorbância - Digestão 3} \\
\hline $\mathbf{0}$ & 0,007 & 0,005 & 0,006 & 0,005 & 0,008 \\
\hline 25 & 0,024 & 0,023 & 0,023 & 0,027 & 0,027 \\
\hline 50 & 0,037 & 0,037 & 0,038 & 0,037 & 0,036 \\
\hline 75 & 0,052 & 0,051 & 0,053 & 0,051 & 0,050 \\
\hline 100 & 0,063 & 0,065 & 0,067 & 0,061 & 0,061 \\
\hline 150 & 0,096 & 0,096 & 0,094 & 0,096 & 0,095 \\
\hline 200 & 0,124 & 0,128 & 0,128 & 0,126 & 0,125 \\
\hline 250 & 0,163 & 0,160 & 0,202 & 0,245 & 0,218 \\
\hline
\end{tabular}

\section{Curva de Calibração - Concentração Baixa}

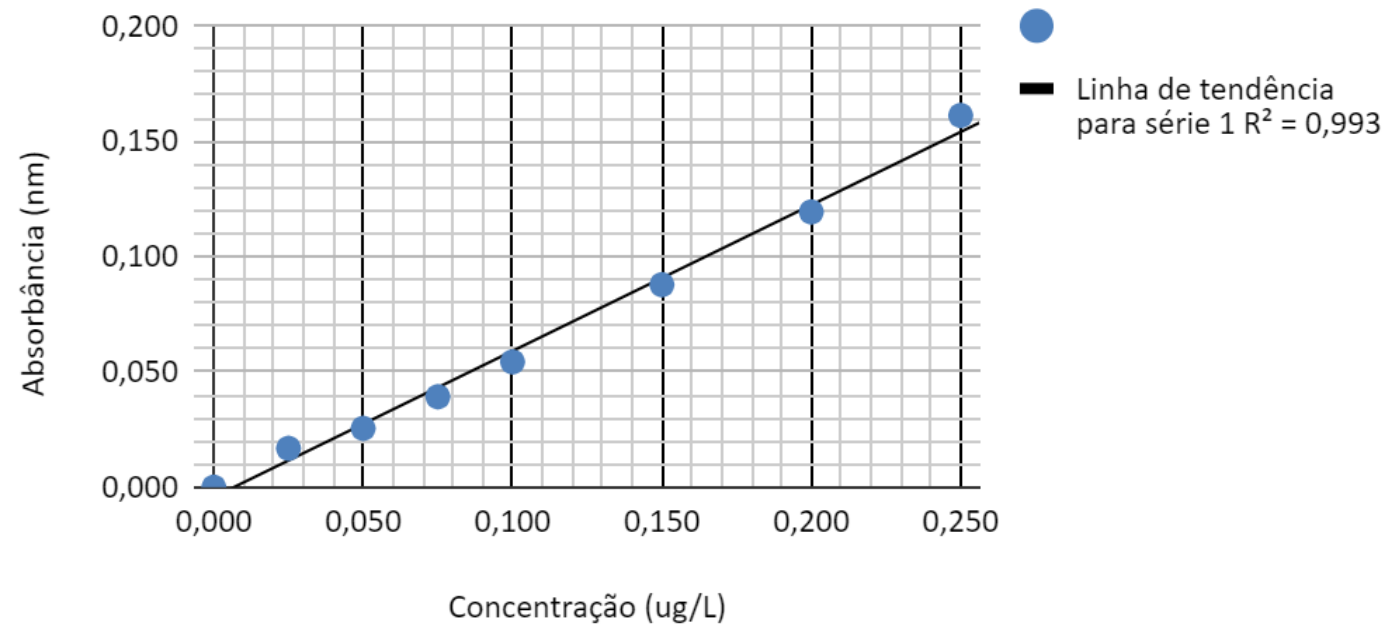

FIGURA C5 - Curva de calibração para concentrações baixas com os valores médios obtidos das três digestões, método 3. 


\subsection{Altas concentrações}

TABELA C14 - Curva de calibração para as concentrações altas, réplica número 1, 2 e 3, método 3.

\begin{tabular}{|c|c|c|c|c|c|}
\hline Concentrações & \multicolumn{5}{|c|}{ Absorbância - Digestão 1} \\
\hline $\mathbf{0}$ & 0,006 & 0,006 & 0,006 & 0,007 & $\overline{0,006}$ \\
\hline 100 & 0,066 & 0,066 & 0,063 & 0,064 & 0,066 \\
\hline 300 & 0,184 & 0,187 & 0,187 & 0,186 & 0,183 \\
\hline 400 & 0,255 & 0,249 & 0,248 & 0,242 & 0,251 \\
\hline 500 & 0,304 & 0,304 & 0,309 & 0,299 & 0,305 \\
\hline 700 & 0,427 & 0,424 & 0,426 & 0,423 & 0,425 \\
\hline 900 & 0,546 & 0,544 & 0,534 & 0,532 & 0,541 \\
\hline 1500 & 0,792 & 0,792 & 0,811 & 0,817 & 0,805 \\
\hline Concentrações & \multicolumn{5}{|c|}{ Absorbância - Digestão 2} \\
\hline $\mathbf{0}$ & 0,006 & 0,006 & 0,006 & 0,006 & 0,005 \\
\hline 100 & 0,060 & 0,066 & 0,068 & 0,056 & 0,064 \\
\hline 300 & 0,186 & 0,189 & 0,186 & 0,189 & 0,187 \\
\hline 400 & 0,244 & 0,247 & 0,245 & 0,246 & 0,251 \\
\hline 500 & 0,315 & 0,304 & 0,305 & 0,313 & 0,303 \\
\hline 700 & 0,422 & 0,422 & 0,425 & 0,424 & 0,417 \\
\hline 900 & 0,543 & 0,541 & 0,544 & 0,542 & 0,546 \\
\hline 1500 & 0,823 & 0,826 & 0,819 & 0,823 & 0,826 \\
\hline Concentrações & \multicolumn{5}{|c|}{ Absorbância - Digestão 3} \\
\hline $\mathbf{0}$ & 0,007 & 0,006 & 0,005 & 0,005 & 0,007 \\
\hline 100 & 0,062 & 0,065 & 0,062 & 0,067 & 0,066 \\
\hline 300 & 0,186 & 0,186 & 0,189 & 0,191 & 0,190 \\
\hline 400 & 0,246 & 0,245 & 0,246 & 0,243 & 0,249 \\
\hline 500 & 0,303 & 0,307 & 0,306 & 0,309 & 0,308 \\
\hline 700 & 0,420 & 0,417 & 0,415 & 0,419 & 0,425 \\
\hline 900 & 0,537 & 0,538 & 0,538 & 0,538 & 0,540 \\
\hline 1500 & 0,814 & 0,812 & 0,817 & 0,816 & 0,817 \\
\hline
\end{tabular}

\section{Curva de Calibração - Concentração Alta}

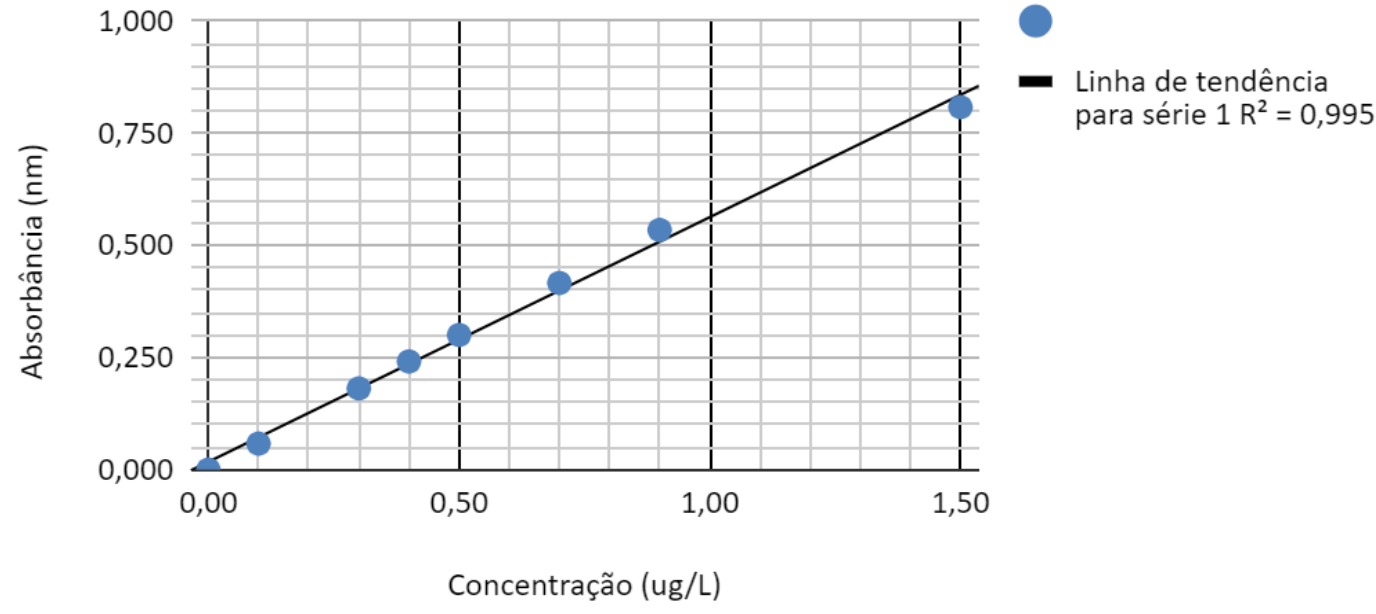

FIGURA C6 - Curva de calibração para concentrações altas com os valores médios obtidos das três digestões, método 3. 


\subsection{Amostras ponto BA1}

TABELA C15 - Absorbâncias obtidas para a amostra do BA1, do Rio Barigui, réplica número 1, 2 e 3, método 3.

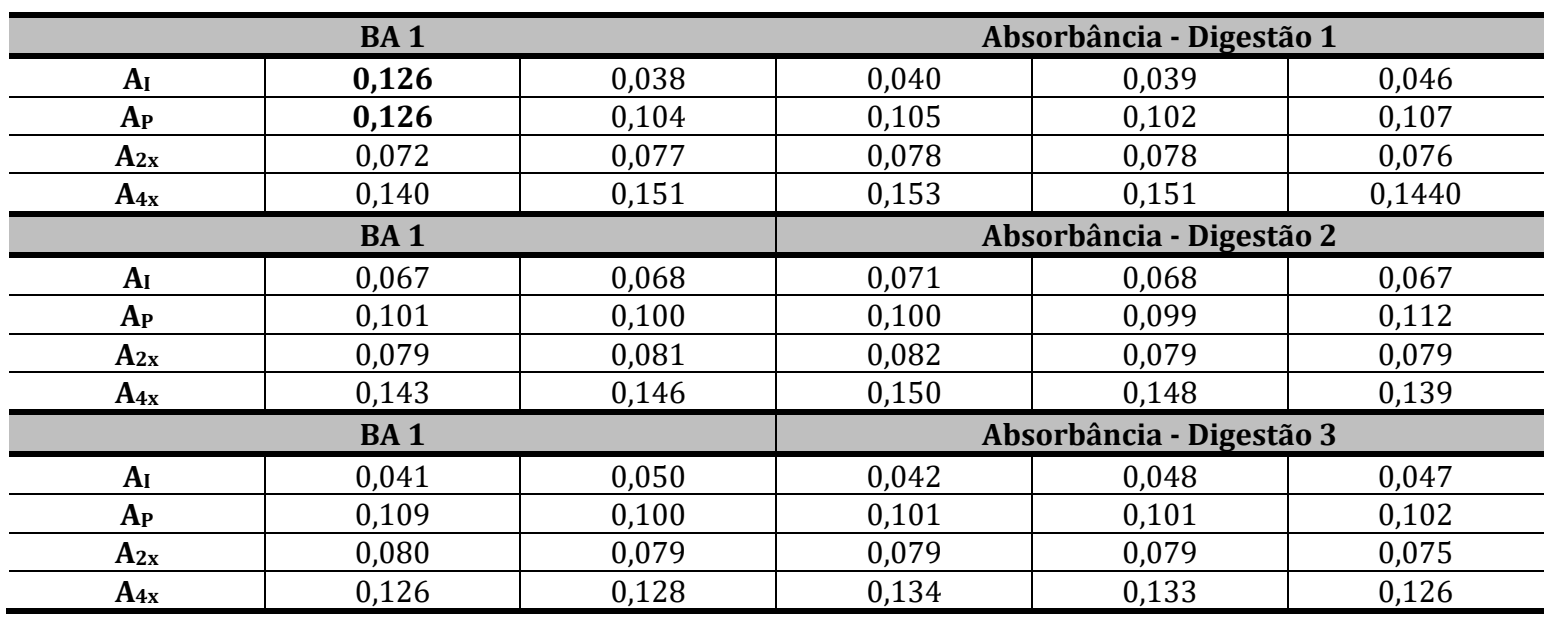

Nota: $A_{I}=$ Amostra inteira. $A_{P}=$ Amostra com adição do padrão de $100 \mathrm{mg} \mathrm{L}^{-1}$ de $P$. $A_{2 x}=$ Amostra concentrada 2 vezes. $A_{4 x}=$ Amostra concentrada 4 vezes

\subsection{Amostras ponto BA3}

TABELA C16 - Absorbâncias obtidas para a amostra do BA3, do Rio Barigui, réplica número 1, 2 e 3, método 3.

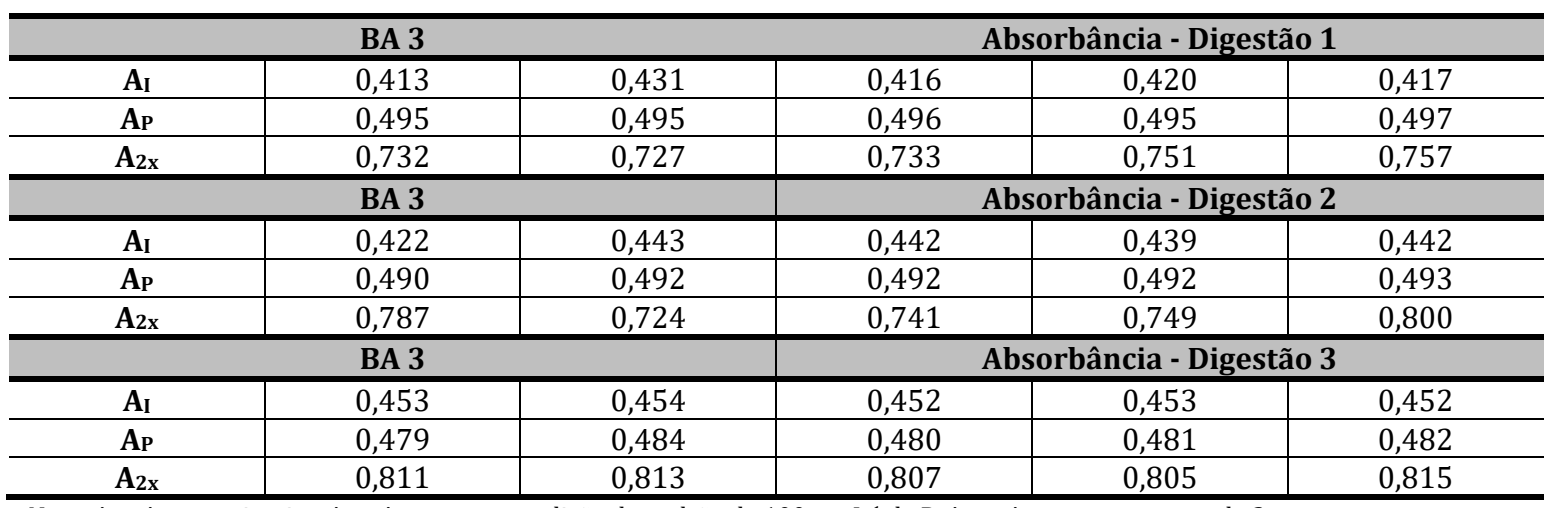

Nota: $A_{I}=$ Amostra inteira. $A_{P}=$ Amostra com adição do padrão de $100 \mathrm{mg} \mathrm{L}^{-1}$ de $P$. $A_{2 x}=$ Amostra concentrada 2 vezes

\subsection{Amostras ponto PASS_2}

TABELA C18 - Absorbâncias obtidas para a amostra do PASS_2, do Rio Passaúna, réplica número 1, 2 e 3 método 3

\begin{tabular}{|c|c|c|c|c|c|}
\hline \multicolumn{3}{|c|}{ PASS_2 } & \multicolumn{3}{|c|}{ Absorbância - Digestão 1} \\
\hline $\mathbf{A}_{\mathrm{I}}$ & 0,182 & 0,069 & 0,062 & 0,061 & 0,063 \\
\hline AP & 0,123 & 0,126 & 0,124 & 0,124 & 0,122 \\
\hline $\mathbf{A}_{2 \mathrm{x}}$ & 0,027 & 0,117 & 0,119 & 0,119 & 0,121 \\
\hline $\mathbf{A}_{4 x}$ & 0,215 & 0,228 & 0,228 & 0,218 & 0,216 \\
\hline \multicolumn{3}{|c|}{$\overline{\text { PASS_2 }}$} & \multicolumn{3}{|c|}{ Absorbância - Digestão 2} \\
\hline$\overline{A_{I}}$ & 0,066 & 0,063 & 0,064 & 0,063 & 0,063 \\
\hline AP & 0,125 & 0,128 & 0,125 & 0,127 & 0,126 \\
\hline $\mathbf{A}_{2 \mathrm{x}}$ & 0,122 & 0,117 & 0,117 & 0,117 & 0,099 \\
\hline $\mathbf{A}_{4 x}$ & 0,219 & 0,226 & 0,216 & 0,214 & 0,219 \\
\hline \multicolumn{3}{|c|}{ PASS_2 } & \multicolumn{3}{|c|}{ Absorbância - Digestão 3} \\
\hline $\mathbf{A}_{\mathrm{I}}$ & 0,058 & 0,061 & 0,061 & 0,061 & 0,063 \\
\hline AP & 0,117 & 0,121 & 0,116 & 0,117 & 0,117 \\
\hline $\mathbf{A}_{2 \mathrm{x}}$ & 0,116 & 0,120 & 0,117 & 0,111 & 0,112 \\
\hline $\mathbf{A}_{4 x}$ & 0,251 & 0,250 & 0,249 & 0,253 & 0,254 \\
\hline
\end{tabular}

